\title{
TECHNICAL ACTIVITIES 1989 SURFACE SCIENCE DIVISION
}

C. J. Powell, Chief

U.S. DEPARTMENT OF COMMERCE Natlonal Institute of standards and Tochnology

NatJonal Measurement Laboratory Center for Atomlc, Molecular, and Optlcal Physlcs Surface Sclence Divislon Galthersburg, MD 20899

Prepared for U.S. DEPARTMENT OF COMMERCE NatIonal Instltute of Standards and Technology Galthersburg, MD 20899

U.S. DEPARTMENT OF COMMERCE Robert A. Mosbacher, Secretary Lee Mercer, Deputy Under Secretary for Technolos

NATIONAL INSTITUTE OF STANDARDS AND TECHNOLOCY

Raymond C. Kammor, Actlng Director 



\title{
TECHNICAL ACTIVITIES 1989 SURFACE SCIENCE DIVISION
}

\author{
C. J. Powell, Chief
}

U.S. DEPARTMENT OF COMMERCE National Institute of Standards and Tochnology National Measurement Laboratory Center for Atomic, Molecular, and Optical Physlcs Surface Sclence DIvision Galthersburg, MD 20899

\section{Prepared for}

U.S. DEPARTMENT OF COMMERCE National Institute of Standards and Technology

Galthersburg, MD 20899

December 1989

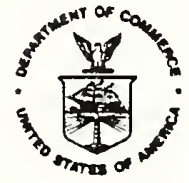

U.S. DEPARTMENT OF COMMERCE Robert A. Mosbacher, Secretary

Lee Mercer, Deputy Under Socretary for Tochnology NATIONAL INSTITUTE OF STANDARDS AND TECHNOLOGY

Raymond G. Kammer, ActIng Director 


\section{ABSTRACT}

This report summarizes technical activities of the NIST Surface Science Division during Fiscal Year 1989. These activities are in three principal areas: surface dynamical processes, thin films and interfaces, and surface spectroscopies and standards. A listing is given of publications, talks, professional committee participation, and professional interactions by the Division staff.

key words: surface chemistry; surface physics; surface science; surface standards 


\section{FOREWORD}

This report is a summary of the technical activities of the NIST Surface Science Division for the period of October 1, 1988 to September 30, 1989. The report was prepared as part of the Annual Report of the Center for Atomic, Molecular, and Optical Physics within the National Measurement Laboratory of NIST.

The technical work of the Division is separated formally into three main program areas: Surface Dynamical Processes, Thin Films and Interfaces, and Surface Spectroscopies and Standards. Reports are given in sections 2, 3, and 4 of work performed in these three program areas. For each area there are a number of separate technical projects and information is given on project objectives, results obtained during the past year, and the nature of planned activities.

Sections 5, 6, and 7 of the report contain listings of papers published papers submitted for publication, patent actions, and listings of talks presented during the year, respectively. Talks presented at the Division's seminars and at Interface Science seminars organized by the Division at NIST are given in section 8 . Information on conferences organized or hosted by Division staff is summarized in section 9. The involvement of Division staff on professional committees is shown in section 10 while internal and external scientific collaborations are described in section 11. Visiting scientists who have worked in the Division during the year are identified in section 12 and the Division staff is listed in section 13.

Further information on the activities of the Division can be obtained by contacting the scientists identified in each project report or by writing Dr. C. J. Powel1, Chemistry B-248, National Institute of Standards and Technology, Gaithersburg, MD 20899 (telephone, 301-975-2534).

NOTE: Certain commercial equipment, instruments, or materials are identified in this report in order to adequately specify the experimental procedure. Such identification does not imply recommendation or endorsement by the National Institute of Standards and Technology nor does it imply that the materials or equipment identified are necessarily the best available for the purpose. 
FOREWORD $\quad$ ii

1. INTRODUCTION 1

A. Background 1

B. Goal, Objectives, and Division Programs 2

2. SURFACE DYNAMICAL PROCESSES GROUP 4

A. Laser Probes of Surface Dynamics 4

B. Studies of Surfaces Using Synchrotron Radiation 7

C. Studies of Molecular Structure and Surface Reactions 10

3. THIN FILMS AND INTERFACES GROUP 12

A. Novel Two-Dimensional Materials 13

B. Structural Analysis of Interfaces 15

C. Ballistic Transport through Interfaces 17

D. Micro-Structural and Micro-Compositional Characterization $\begin{array}{ll}\text { of Novel Materials } & 17\end{array}$

4. SURFACE SPECTROSCOPIES AND STANDARDS GROUP 20

A. Theory of Dynamical Molecular Processes at Surfaces 20

B. Ion-Surface Interactions $\quad 22$

C. Electron Spectroscopy of Surfaces 26

D. Surface-Analysis Standards Committees 28

5. PUBLICATIONS 29

A. Publications of Past Year 29

B. Publications in Progress 33 
C. Recent Publications of New Staff Members Resulting from Previous Positions

6. PATENT ACTIONS 38

7. TALKS

8. SURFACE SCIENCE DIVISION SEMINARS AND INTERFACE SCIENCE SEMINARS

9. CONFERENCES ORGANIZED

10. TECHNICAL AND PROFESSIONAL COMMITTEE PARTICIPATION AND LEADERSHIP

11. PROFESSIONAL INTERACTIONS, CONSULTING AND ADVISORY SERVICES

12. GUEST SCIENTISTS

13. SURFACE SCIENCE DIVISION STAFF 


\title{
SURFACE SCIENCE DIVISION
}

\author{
SUMMARY OF ACTIVITIES
}

Fiscal Year 1989

\section{INTRODUCTION}

\section{A. Background}

Over the last decade, there has been a dramatic growth of surface science and its applications. This growth and its significance have been documented in two major reports, the Pimentel report to the National Academy of Sciences on "Opportunities in Chemistry" (National Academy Press, Washington, D.C. 1985) and the Brinkman report to the National Academy of Sciences on "Physics Through the 1990's" (National Academy Press, Washington, D.C., 1986). Both reports describe in some detail the pervasive role of surfaces, interfaces, and thin films in frontier scientific research and in major technological applications. The scientific opportunities range from studies of the dynamical processes involved when atoms and molecules interact with surfaces to heterogeneous catalysis, physical and chemical properties of clusters, fabrication and characterization of novel thin-film and superlattice materials, and surface critical phenomena, among many other topics. A principal goal of investigations in these areas is to obtain knowledge at a fundamental atomic and molecular level of surface and interface properties and processes. The technological applications include microelectronics, information processing, catalysis, corrosion, coatings, adhesion, wear, and biomaterials as well as areas of national concern such as energy generation, transportation, environmental pollution, space technology, and national security. A strong driving force in both the scientific and technological sectors is the need for improved U.S. economic competitiveness; in a 1987 analysis, the U.S. Department of Commerce has identified surfaces and thin films as having major significance for the development of new technologies.

Many measurement techniques are used to characterize surface properties (such as composition, atomic structure, electronic structure, defects, and topography) and surface processes (such as reactions, diffusion, segregation, and exposure to beams of ions, neutrals, photons, and electrons). A choice of one or more techniques is made typically on the basis of the property to be measured, the specimen material, and the specific needs (e.g., spatial resolution, chemical information, sensitivity, degree of difficulty, and cost). New techniques are also being developed to characterize the properties of thin-film materials and the dynamics of molecule-surface interactions. Many of the techniques are continually being refined and extended, as are the concepts on which they are based. The concepts and techniques that have proven successful for surface characterization are also being applied to the characterization of interfaces and thin films. In many such applications, surface material is removed by ion sputtering or other means to expose an interface or other region of interest. While very useful, artifacts can generally be 
introduced by the removal process and there is now a growing need for nondestructive techniques for interface characterization, particularly with the sensitivity, elemental specificity, and spatial resolution of current surface-characterization methods.

The most common type of surface measurement is the determination of surface composition. Most surface analyses now are qualitative but there is a growing demand for quantitative analyses with improved accuracy. At the present time, there are few standard procedures and limited reference data and reference materials. A variety of techniques are employed for the determination of surface atomic structure, surface electronic structure, and for investigations of surface processes such as reactions, diffusion, segregation, etc. Theories of the measurement process need to be developed for the newer techniques. For all techniques, there is a need for relevant procedures, tests to establish measurement reliability, and applicable reference data. In most cases, the measurement science needs to be developed since knowledge of the key concepts and parameters is often extremely limited. Some concepts and data are synthesized and developed from those of disciplines such as atomic and molecular physics, chemistry, and materials science.

\section{B. Goal, Objectives and Division Programs}

The goal of the Surface Science Division is to improve the quality of existing surface-characterization measurements and to extend the present capability. Specific objectives of the Division are:

(1) Perform experimental and theoretical research in surface science to provide a scientific base for surface-measurement methodology;

(2) Develop measurement methods and provide properties data for the physical and chemical characterization of surfaces and surface processes to meet identified needs of industry, government, and other groups;

(3) Develop reference procedures, reference data, and reference materials in cooperation with national and international standards organizations; and

(4) Develop expertise in selected new areas of surface science in order that NIST can provide measurement services where needs are anticipated in the near future.

While the Division has a broad mandate, its resources are limited and it has to concentrate its activities in areas considered to be of high priority. The Division is now organized into three Groups (Surface Dynamical Processes, Thin Films and Interfaces, and Surface Spectroscopies and Standards) which represent the three principal directions of the current program.

Descriptions are given in the following pages of technical work performed over the past year. These are followed by lists of publications, 
patent actions, invited lectures, seminars held at NIST, external conferences organized, involvement with professional groups, and collaborations with other scientists. In addition to a regular series of Division seminars on surface science topics, the Division has been active in establishing a NIST-wide series of seminars on interface science. A successful series of discussion meetings was also held within the Division on scattering phenomena.

Some technical highlights of the past year are listed below; further details of these accomplishments are given in the indicated sections of this report.

- Studies of laser-induced desorption of NO from a Si(111) surface have shown the importance of thermalized band-edge carriers in the desorption process (section 2.A)

- The ellipsoidal-mirror analyzer has been installed at SURF-II; initial tests indicate that the analyzer is operating within design expectations (section 2.B)

- X-ray photoelectron spectroscopy has shown how fully chlorinated silanes can be used to prepare silicon films by chemical vapor deposition; the chlorinated silanes are much safer to handle than silane (section 2.C)

- Adsorbed gases can be used as surfactants to modify the morphology of epitaxial films and thereby to permit a new degree of control at the atomic level on thin-film microstructures (section 3.A)

- The technique of grazing-angle $x$-ray diffraction has been used to determine the roughness spectrum of a germanium surface (section 3. B)

- Calculations of ballistic electron transport have shown the transmission probability for the two structural forms of siliconnickel disilicide interfaces is too low to be useful for a proposed new type of transistor (section 3.C)

- Atom-probe field-ion microscopy studies have shown that the surface layers of europium 1-2-3 superconducting oxides lose oxygen at room temperature but not at $85 \mathrm{~K}$ or below (section $3 . \mathrm{D}$ )

- A new theory has been developed that successfully accounts for a giant enhancement in electron-resonance-assisted desorption ( $\operatorname{section} 4 . \mathrm{A})$

- A new scanning scattering microscope has been developed (and a patent application filed) to measure surface roughness with a height sensitivity of about $1 \mathrm{~nm}$ (section 4.B) 
New calculations of inelastic mean free paths of low-energy electrons in solids show substantial differences amongst materials in the 50-200 eV range (section 4.C)

\section{SURFACE DYNAMICAL PROCESSES GROUP}

As greater control and predictability of physical properties of surfaces are sought, the surface science community is increasingly turning to a molecular level understanding of surface probes, surface properties and surface reactions. Within the Surface Dynamical Processes Group, a variety of approaches are utilized to obtain information on the microscopic behavior of surfaces. The techniques which are employed range from laser probes of surface reactions to synchrotron based measurements of surface electronic structure and reactivity. Systems of interest have ranged from small molecules adsorbed on metal and semiconductor single crystals, to compositionally controlled high temperature superconductors and chemical etching of electronic materials.

A. Laser Probes of Surface Dynamics (R. R. Cavanagh, J. D. Beckerle, S. A. Buntin, and L. R. Richter together with M. P. Casassa, E. J. Heilweil, D. S. King, and J. C. Stephenson of the Molecular Spectroscopy Division)

Lasers have emerged as extremely powerful tools for unraveling the complex properties of molecular processes at surfaces. By exploiting both the short pulse duration and the narrow spectral linewidths which are characteristic of lasers, it is possible to follow and/or induce adsorbatespecific surface processes. The prospects for capitalizing on the accompanying non-thermal behavior in such transient events has made this an extremely active area of surface science. Within the present program, two distinct aspects of laser/surface interactions are addressed. The first area of the program involves the complete characterization, using quantumstate-specific techniques, of the desorbed molecules in laser-induced desorption. These studies provide insight into the potential energy surfaces relevant to desorption, and the pathways for optical excitation. In a second area of the program, the time-resolved response of clean and adsorbate-covered surfaces are examined. The excited state lifetimes of vibrationally excited adsorbates are measured in an infrared pump-probe configuration. These experiments provide direct information on the rate at which selectively excited molecular populations decay.

Laser Induced Desorption (R. R. Cavanagh, S. A. Buntin and L. J. Richter together with D. S. King of the Molecular Spectroscopy Division).

Experiments examining laser-induced desorption (LID) of NO from platinum (111) have recently been completed. Laser-induced fluorescence (LIF) was used to probe the partitioning of energy between the various degrees of freedom of the desorbed NO. The desorption-laser wavelength dependence of the kinetic energy and vibrational state distributions has been examined at 1906, 1064, 532 and $355 \mathrm{~nm}$. Combined with measurements of 
the desorption yield as a function of angle of incidence of the desorption laser beam, these results provided the first unambiguous proof of the role of "hot" carriers in the chemistry of molecules bound to metal surfaces. Recent theoretical modeling in collaboration with J. W. Gadzuk suggests that a short lived $\left(10^{-15} \mathrm{~s}\right)$ negative ion resonance could account for the observed desorption yield. The experimental studies determined that the spin-orbit populations were strongly inverted, and that the rotational population exhibited a pronounced low J plateau. Our present understanding of the desorption process indicates that these non-Boltzmann internal-state populations are characteristic of the molecular ejection pathway. The site-specific nature of this desorption process, and the highly non-

Boltzmann populations associated with this channel, suggest the sensitivity of surface excited states to subtle details of gas/surface interactions. More significant, however, was the clear demonstration that the short-lived transients associated with hot carriers on metal surfaces can dominate chemical events.

Similar LIF studies of the LID of NO/Si(111) have been undertaken in order to better characterize the role of carrier-induced surface reactions. We have discovered that there is a strong coverage dependence in the LID signals (yield per incident photon, relative yield at different wavelengths, internal state populations, etc.). For instance, the relative NO population in the first excited vibrational state increases by a factor of three as the NO coverage increases from a dilute limit to saturation $(v=1 / v=0: 0.19 \pm 0.09$ and $0.64 \pm 0.24$, respectively). Data acquired to date indicates that the kinetic energy of the desorbed No greatly exceeds the peak surface temperature ( $1000 \mathrm{~K}$ vs. $100 \mathrm{~K}$ ) and that the kinetic energy increases with increasing rotational energy. Figure 1 displays the internal state population for a low coverage of No. While under population of the $F_{2}$ levels compared to the $F_{1}$ levels is apparent, within the $F_{1}$ level the rotational state population can be described by a Boltzmann distribution with $T_{r o t}=200 \mathrm{~K}$. By increasing the No coverage, the population of the $F_{1}$ and $F_{2}$ states becomes equilibrated with the nuclear rotations, and the population can be described as $T_{r \circ t}=600 \mathrm{~K}$. The details of the coverage dependence of the internal states are still under study. The lack of a marked wavelength dependence in the desorption dynamics at low coverage has suggested that the desorption is driven by thermalized band-edge carriers. At higher coverages, the dynamics become wavelength sensitive, an effect which is currently under study. Future work is anticipated where the influence of crystal face and excitation below the gap (Si(100) and GaAs(110), respectively) will be investigated. 


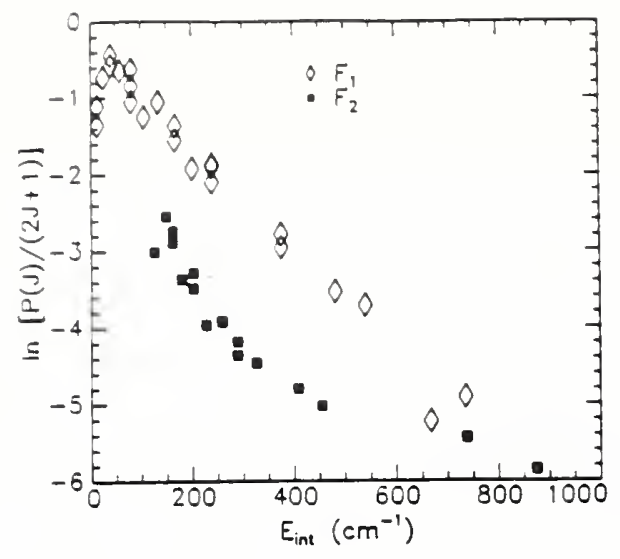

Fig. 1. Internal state distribution for NO in $\mathrm{v}=0$ produced via laserinduced desorption of low coverages of NO on $\mathrm{Si}(111)$ at $95 \mathrm{~K}$ with $355 \mathrm{~nm}$ radiation. The high-energy spinorbit state $F_{2}$ has significantly less population than the ground spin-orbit state $F_{1}$ for NO with comparable internal energy $\left(E_{\text {int }} \equiv\right.$ spin-orbit + rotational energies).

Extension of existing state-specific detection techniques to include the detection of gas-phase $C O$ are in progress. The generation of narrowband vacuum ultraviolet (VUV) laser radiation in the spectral region of 140-155 nm is necessary to detect CO by LIF. The method of choice is twophoton resonance-enhanced four-wave sum-frequency generation in $\mathrm{Mg}$ vapor. In this nonlinear frequency conversion process, three photons from two dye lasers are combined in a heat pipe to generate a single VUV photon ( $\omega_{V u v}=$ $\left.2 \omega_{1}+\omega_{2}\right)$. The lasers and heat pipe facilities were procured during the past year. In addition, a VUV test apparatus has been constructed and detector optimization (for both VUV signal and CO LIF) is currently underway for frequency tripling in Xe. It is anticipated that the first tests using $\mathrm{Mg}$ vapor for VUV generation will take place in the fall of 1989, with desorption studies commencing shortly thereafter. In these experiments, CO desorption will be investigated for a number of systems. Specifically, probing the dynamics of laser heating and carrier-driven desorption for metal-based systems such as CO/Pt(111) and CO/K/Pt(111) will clarify the influence of adsorbate properties (eg. electronic structure, binding energies, etc.) on these processes. In addition, studies of the photofragmentation/photodesorption of $\mathrm{CO}$ from Mo(CO) ${ }_{6} / \mathrm{Si}(111)$ will provide insight into adsorbate-moderated energy relaxation at surfaces. This work was supported in part by the U.S. Department of Energy.

Time-Resolved Vibrational Relaxation at Surfaces (R. R. Cavanagh and J. D. Beckerle together with M. P. Casassa, E. J. Heilweil, and J. C. Stephenson of the Molecular Spectroscopy Division)

Vibrational relaxation times $\left(T_{1}\right)$ have been measured for $C O$ on $R h$ and Pt particles supported on $\mathrm{SiO}_{2}$. By configuring a 2 picosecond tunable infrared system for pump-probe measurements, it has been possible to characterize the temperature, polarization, and wavelength dependence of $\mathrm{T}_{1}$ for these $\mathrm{CO} / \mathrm{Metal} / \mathrm{SiO}_{2}$ specimens. Comparison to model metal carbonyl compounds in solution and supported on $\mathrm{SiO}_{2}$ indicated that rapid $(\approx 7 \pm 2 \mathrm{ps})$ new decay processes were involved. Comparison to existing theories and frequency domain experiments on single-crystal surfaces has suggested that relaxation through low-lying electron-hole $(e / h)$ pair excitations could be responsible for the observed time scale. In collaboration with $\mathrm{J}$. W. Gadzuk, theoretical modeling of the electronic levels of the metal clusters as a function of particle size has demonstrated that the present particles $(\approx 30 \AA)$ fall near the size threshold for infrared excitation of $\mathrm{e} / \mathrm{h}$ pairs. 
Work in the area of vibrational relaxation has now shown that experiments on well-characterized single-crystal surfaces are essential for establishing the site selectivity and the role of e/h pairs in vibrational relaxation. Based on the expertise acquired over the past several years, it is now apparent that single-reflection picosecond infrared experiments are technologically feasible. An ultra high vacuum (UHV) system dedicated to these experiments is now operational. Conventional surface diagnostics have been applied to platinum and palladium surfaces in order to prepare specimens for Fourier Transform Infrared (FTIR) spectral measurements and for transient picosecond infrared experiments. Initial measurements of the coverage and temperature dependence of the CO/Pt(111) system were made using a commercial FTIR spectrometer with a resolution of $0.125 \mathrm{~cm}^{-1}$. The results of these experiments have confirmed previously published reports of both the coverage- and temperature-dependent perturbations of the spectral widths and positions.

Initial tests of the UHV system with the 2 ps infrared laser are in progress. Optics have been configured for the single-reflection experiments, and tests of pulse-to-pulse stability and random noise sources are well underway. The picosecond laser system has recently been used to record the infrared spectrum of $\mathrm{CO} / \mathrm{Pt}(111)$, indicating a peak position and signal strength in good agreement with the FTIR results. Preliminary data indicated a weak transient (signal/noise $\approx 1$ ) in the pump-probe measurements of vibrational relaxation for this system at $2105 \mathrm{~cm}^{-1}$ for $\theta_{\mathrm{co}}$ $=0.5 \mathrm{ML}$. Work is presently underway to further reduce the background noise and increase the dynamic range in this system.

These experiments will provide the first time-resolved characterization of energy transfer for a molecule directly bound to a well characterized site of a metal surface. It is at these short molecule-metal distances where not only classical electrodynamic theories break down, but where surface chemistry takes place. The knowledge gained in this generation of time-resolved experiments should greatly aid in the development of new measurement technologies capable of directly determining the dynamics of molecular energy-transfer processes at surfaces. This work was supported in part by the Air Force Office of Scientific Research.

B. Studies of Surfaces Using Synchrotron Radiation (R. L. Kurtz, D. R. Mueller, S. W. Robey, R. L. Stockbauer, T. E. Madey, E. L. RomanGarcia," A. Shih," and Q. Wang*)

The major goals of this effort are to determine the electronic structure of surfaces, thin-films, and adsorbates using variable-wavelength photoelectron spectroscopy and to identify the electronic excitations which lead to ion desorption. Synchrotron radiation provides the incident photons for both types of experiments with its tunability being its greatest asset. In the photoemission experiments, the tunability allows us to probe resonances which can be used to identify peaks in the valence-band

* Guest Scientist 
spectra as well as to increase sensitivity to minority states on the surface. In the ion yield measurements, the tunability allows us to obtain ion yield data (ion intensity as a function of photon energy) which are correlated with photoemission results to identify the excitations which initiate the ion desorption process.

Photoemission Studies of High- $\mathrm{T}_{c}$ Superconductors ( $\mathrm{S}$. W. Robey, R. L. Kurtz, R. L. Stockbauer, D. R. Mueller," and A. Shih")

One of the basic questions concerning the new high- $T_{c}$ superconductors is the nature of the electronic interactions which lead to the superconductivity. The answer to this question lies in knowing the electronic structure of the new material. Photoemission spectroscopy is a powerful technique for elucidating electronic properties and has provided data which can be compared directly with band structure calculations.

Our effort over the past year has been directed towards the design and construction of a research scale molecular-beam epitaxy system for the production of thin films of these materials by coevaporation. This system will be coupled to facilities for resonant photoemission studies (at the NIST SURF II synchrotron) and to various other electron spectroscopies and characterization techniques for studies of the growth and epitaxy of the superconducting oxides, as well as for investigations of the electronic structure of well-characterized thin films. Detailed investigations of the factors affecting the epitaxial growth on different substrates, the effects of substrate interactions and the effects of buffer layers (e.g., barium fluoride) can be pursued. It is also expected that important information will be gained in the area of surface interactions of the high-temperature superconducting materials with other materials, such as metals, information which is of importance for the realization of devices from these complex oxides.

The necessary ultra-high vacuum chamber has been designed and constructed and will provide for the installation of up to six different deposition sources at one time. Each source will be individually monitored and controlled by means of electron impact emission sensors for measurement of evaporation rates for different materials. Evaporation sources have been constructed and tested and the implementation of control by means of a MacIntosh II PC is currently underway. This work has been supported in part by the Office of Naval Research.

Molecular Adsorption on Oxide Surfaces (R. L. Kurtz, R. L. Stockbauer, E. L. Roman-Garcia," and T. E. Madey)

Our long-term interest in the electronic structure and chemistry of oxide surfaces continues with a synchrotron-radiation photoemission study of the interaction of molecules with defective and nearly-perfect $\mathrm{TiO}_{2}(110)$ surfaces at temperatures between 160 and $300 \mathrm{~K}$. This work is performed as part of a co-operative agreement between the United States and Spain and involves a collaboration with the Instituto Ciencia de Materiales, CSIC, Madrid. Typically, preliminary photoemission and thermal desorption 
studies are performed in Spain while the resonant photoemission studies are performed in a surface analysis chamber at the NIST SURF II storage ring.

We have completed a study of $\mathrm{H}_{2} \mathrm{O}$ adsorption on $\mathrm{TiO}_{2}$ (110) which has suggested a new model for dissociative adsorption on oxide surfaces at low temperatures. The work has continued with a recent investigation of lowtemperature adsorption and dissociation of $\mathrm{NH}_{3}$ on $\mathrm{TiO}_{2}(110)$.

Electron Attenuation Lengths in Condensed Molecular Solids (R. L. Kurtz, R. L. Stockbauer, and Q. Wang ${ }^{*}$ )

Values of electron attenuation lengths (ALs) in different materials and at different electron energies are needed for quantitative surface analyses by Auger-electron spectroscopy and $x$-ray photoelectron spectroscopy. We have continued to improve a method developed earlier for measuring ALs in condensed molecular solids, materials for which the AL data base is extremely sparse.

Films of water, methanol, ethanol, and acetone have been condensed on a substrate at liquid-nitrogen temperature. The attenuation of photoelectrons from the substrate valence band has been measured as a function of film thickness to obtain AL values over the electron energy range 28-180 eV. We have examined the effects of several parameters in our experiments. First, we have substituted nickel for the copper substrate used previously. Second, the effect of the measurement geometry was studied by comparing and contrasting results obtained with various masking arrangements for our cylindrical-mirror analyzer. Finally, we have explored different methods for depositing the overlayer film and found that continuous dosing with a microcapillary array during the acquisition of photoemission spectra resulted in data of improved quality.

\section{Ellipsoidal-Mirror Analyzer (R. L. Kurtz and R. L. Stockbauer)}

Our group has played a strong role in developing techniques and instrumentation for studies of both electron- and photon-stimulated desorption processes. Our interests range from studies of desorption and fragmentation of small molecules adsorbed on clean metallic substrates to desorption from more complex oxide surfaces where ejection of both substrate and adsorbed species are of interest. These studies provide basic information on bonding and structure of these surfaces as well as on the dynamical effects occurring during the stimulated desorption process. Toward this end, a large effort has been devoted to the development of an ellipsoidal-mirror analyzer (EMA) based on the design of Eastman. The instrument has now been installed on beam line 1 at the NIST SURF-II synchrotron light source. Initial testing indicates that the analyzer is operating generally within design expectations. Extensive software development has been completed which allows the analyzer to be used for a variety of electron and ion spectroscopies and to provide control of auxiliary functions. Initial studies on clean and $\mathrm{NH}_{3}$-covered $\mathrm{Ru}(0001)$ have been initiated and preliminary angle-integrated photoelectron and photon-stimulated ion desorption spectra have been obtained. 
The next phase in making the instrument fully operational will involve the refinement of the angle-resolving capabilities. This will provide us with the ability to measure desorbed ion kinetic energy distributions as a function of desorption angle giving information on substrate dynamic response and reneutralization effects. Such measurements together with time-of-flight techniques will permit studies of the angular distributions of ions of different masses and comparative studies of yields for positive and negative ions. In contrast with measurement techniques used to date, this analyzer will permit simultaneous measurement of desorbing ion mass, and the kinetic energy and angular distribution as a function of the incident photon or electron energy that stimulates the desorption process. Measurements of this type should result in a more complete description of the systems of interest than has been realized previously.

This instrument will be our primary research instrument in the near future and, in addition to the ion desorption studies, will be used for angle-integrated photoelectron studies of a wide range of materials ranging from semiconductors to high-temperature superconductors.

\section{Molecular Dynamics Studies of Ion Desorption Phenomena (R. L. Kurtz)}

Through experimental results obtained on oxide surfaces, our group has proposed that surface structures of complex materials such as steps and local site defects may be elucidated by studies of ion desorption angular distributions. In order to further investigate this possibility, we have extended the work of Walkup by producing software to calculate ion desorption trajectories for ionic materials. This allows us to investigate a wide range of surface structures and defects and calculate the resulting ion desorption trajectories. This modeling will allow us to determine the connection between proposed models of surface structure and actual measured ion desorption images. Presently, trajectories are being run for a range of surface structures for $\mathrm{TiO}_{2}$ and $\mathrm{MgO}$. In the future, effects of image charge and reneutralization will be included to provide a connection to the measurements of ion kinetic energy vs. desorption angle measured on such systems using the ellipsoidal-mirror analyzer.

C. Studies of Molecular Structure and Surface Reactions (J. A. Yarmoff, S. A. Joyce, L. J. Whitman, and T. E. Madey)

We have used a variety of experimental techniques to study the structure of adsorbed molecules on surfaces and to determine the mechanisms of surface reactions. The systems chosen for study are of interest in catalytic surface chemistry, semiconductor processing, and tribology.

Coadsorption of $\mathrm{PF}_{3}$ and $\mathrm{K}$ on $\mathrm{Ru}(0001$ ) (S. A. Joyce, J. A. Yarmoff, and T. E. Madey)

We have studied the coadsorption of $P_{3}$ and $K$ on a Ru(0001) surface using both positive- and negative-ion electron stimulated desorption ion angular distributions (ESDIAD), thermal desorption spectroscopy, low-energy electron diffraction, and soft $x$-ray photoemission. In the absence of 
further measurements of the PSD of fluorine at the $F$ is edge. By comparison of the near-edge $x$-ray absorption fine structure (NEXAFS) signal to the PSD yield, we have determined the relative PSD yields of fluorine originating from $\mathrm{SiF}$ versus $\mathrm{SiF}_{3}$ surface sites.

Near-Edge Studies of $\mathrm{CaF}_{2}$ Surfaces and $\mathrm{CaF}_{2} / \mathrm{Si}(111)$ Interfaces (J. A. Yarmoff)

In collaboration with Dr. F. Himpsel of the IBM Watson Research Center, we have investigated the near-edge structure at the $\mathrm{Ca} 3 \mathrm{p}$ edge in $\mathrm{CaF}_{2}$ with NEXAFS and PSD. $\mathrm{CaF}_{2}$ grown on $\mathrm{Si}$ is a good model system of a semiconductor/insulator interface, since the lattice match (of 0.68 ) allows for the growth of an atomically abrupt interface. There are a variety of transitions which occur at the $\mathrm{Ca} 3 \mathrm{p}$ edge which arise from crystal-field splitting in the bulk material. There are additional features which are due to the bonding at the $\mathrm{Si}$ interface, states localized at the $\mathrm{CaF}_{2}$ surface, and defect sites. We have performed a thorough investigation of this system and identified the origin of each observed feature.

\section{Resonant Photoemission from $\mathrm{MoS}_{2}$ Surfaces (J. A. Yarmoff)}

$\mathrm{MoS}_{2}$ is an important tribological material due to its layered crystal structure. This crystal structure also leads to some interesting chemical properties at its surface. $\mathrm{MoS}_{2}$ is an extremely inert material with respect to light elements, but does react vigorously with some adsorbed metals. In addition to previous studies of ion-beam damage effects and metal adsorption in collaboration with $\mathrm{Dr}$. J. R. Lince of the Aerospace Corporation, we have performed some new measurements of the resonant photoemission of this material. These measurements will help to understand the valence electronic structure of $\mathrm{MoS}_{2}$.

\section{THIN FILMS AND INTERFACES GROUP}

In recent years it has become clear that thin films and interfaces not only can have novel physical properties but are also of considerable technological importance. Structure at the atomic level is the key to many properties and to the performance of solid-state materials and devices. The Thin Films and Interfaces Group is concerned with the structural aspects of epitaxial growth of thin-film systems, artificially structured or atomically engineered novel materials, electron transport across interfaces, and buried interfaces. As much as possible, the structural parameters are related to specific properties of interest. Examples of recent work are the achievement of improved magnetic properties of $\mathrm{Fe}-\mathrm{Cu}$ sandwich structures, the prediction of a novel x-ray mirror to detect the Bragg condition, the prediction of a silicon-silicide interface with improved ballistic-electron transport properties, and the observation that the europium 1-2-3 superconducting material retained its surface stoichiometry on exposure to vacuum only when cooled to liquid-nitrogen temperature. 
coadsorbed potassium, positive and negative-ion ESDIAD show highly anisotropic, off-normal fluorine ion emission from $\mathrm{PF}_{3}$ demonstrating that the P-F bonds are oriented away from the surface normal. However, in the presence of $\mathrm{K}$, both the positive- and negative-ion ESDIAD images show large amounts of normal emission indicating some reorientation of the $\mathrm{P}-\mathrm{F}$ bonds along the surface normal. The photoemission results indicate that the chemistry of the $\mathrm{PF}_{3}$ adsorption is significantly altered by the presence of $\mathrm{K}$. In addition to changes in the desorbed-ion angular distributions, we observe dramatic changes in the yields of the positive and negative ions as a function of potassium coverage, as well as the emergence of a species which we identify as a metastable, neutral fluorine. Qualitatively similar changes in desorption yields have also been observed from coadsorbed $\mathrm{HF}$ and $K$. This work has been supported in part by the U.S. Department of Energy.

Chemisorption of Chlorosilanes on Silicon (L. J. Whitman, S. A. Joyce, and J.A. Yarmoff)

Motivated by the desire for a safer alternative to $\mathrm{SiH}_{4}$ and $\mathrm{SiH}_{2} \mathrm{Cl}_{2}$ for Si thin-film growth via chemical vapor deposition (CVD), a number of studies have demonstrated that films can be efficiently deposited with the fully chlorinated silanes, $\mathrm{SiCl}_{4}$ and $\mathrm{Si}_{2} \mathrm{Cl}_{6}$, which are relatively stable liquids under ambient conditions. Little is known, however, about the basic chemical interactions between chlorosilanes and $\mathrm{Si}$ surfaces. We have studied the chemisorption of $\mathrm{SiCl}_{4}, \mathrm{Si}_{2} \mathrm{Cl}_{6}$ and chlorine on single-crystal $\mathrm{Si}$ surfaces in ultra-high vacuum employing soft $\mathrm{x}$-ray photoemission spectroscopy, thermal desorption spectroscopy, and Auger electron spectroscopy. We find that $\mathrm{SiCl}_{4}$ dissociatively chemisorbs at room temperature on $\mathrm{Si}(111)-7 \times 7$ with an extremely low sticking coefficient, forming only $\mathrm{SiCl}$ moieties on the surface. In contrast, $\mathrm{Si}_{2} \mathrm{Cl}_{6}$ chemisorbs with near-unit probability, partly dissociating into $\mathrm{SiCl}, \mathrm{SiCl}_{2}$, and $\mathrm{SiCl}_{3}$. Upon heating, most of the adsorbed $\mathrm{Cl}$ desorbs near $650^{\circ} \mathrm{C}$ as $\mathrm{SiCl}_{2}$ with no appreciable $\mathrm{Cl}_{2}$ desorption. This result implies that without an additional reactant (e.g., hydrogen) to remove adsorbed $\mathrm{Cl}$, these fully chlorinated silanes will etch silicon. Similar results are observed with $\mathrm{Si}(100)-2 \times 1$.

Photon-Stimulated Desorption of Fluorine from Silicon (S. A. Joyce and J. A. Yarmoff)

We have continued our investigations into the photon-stimulated desorption (PSD) of fluorine from silicon surfaces. Our previous work on monolayer amounts of fluorine adsorbed on silicon had shown how the PSD onsets at the Si 2p edge provide a measure of the unoccupied density of states of the bonding silicon atoms. We have extended this technique to measurements of the Si $2 \mathrm{p}$ edge for surfaces which had been subjected to steady-state etching by $\mathrm{XeF}_{2}$. Photoemission measurements of this surface show a thick reaction layer comprised of both silicon monofluoride (SiF) and trifluoride $\left(\mathrm{SiF}_{3}\right)$, and a small amount of difluoride $\left(\mathrm{SiF}_{2}\right)$.

Photoemission, however, is unable to measure the spatial distributions within this layer. With PSD, we see strong signals at the $2 \mathrm{p}$ edge due to both silicon monofluoride and trifluoride, which indicates that the spatial distribution of the layer is relatively homogeneous. We have also made 
energy metals to wet the surface of low-surface-free-energy substrates. This is a generic problem in epitaxy since such free-energy differences are a common driving force behind unwanted effects such as agglomeration or interdiffusion. These effects often prevent the growth of atomically sharp interfaces (a common goal in epitaxy, as well as one of the most elementary examples of a structural arrangement of atoms over which we would like to gain control).

Figure 2 illustrates one aspect of how adsorbed gases provide a degree of control. A monolayer (ML) of $\mathrm{Fe}$ or $\mathrm{Ni}$, deposited on clean $\mathrm{Cu}(100)$ at room temperature, tends to agglomerate; at higher temperatures interdiffussion occurs. However, if half a monolayer of oxygen is preadsorbed on the $\mathrm{Cu}(100)$, the $\mathrm{Fe}$ or $\mathrm{Ni}$ will wet the substrate in order to maximize the bonding between the transition metal and oxygen, as in Fig. $2 \mathrm{~b}$. Since Fig. $2 \mathrm{~b}$ is the ground state of the system, annealing does not produce interdiffusion. The oxygen is thus acting as a surfactant to modify the balance of surface and interface free energies that control the epitaxial growth mode. In addition, we have found that adsorbed oxygen has a strong tendency to float out onto the surface of a subsequently deposited film without significantly affecting the epitaxial order. Similar adsorbate-induced wetting and adsorbate floating-out have been observed for a variety of other adsorbates and metal-metal systems; these effects should therefore be of general applicability in facilitating epitaxial growth.

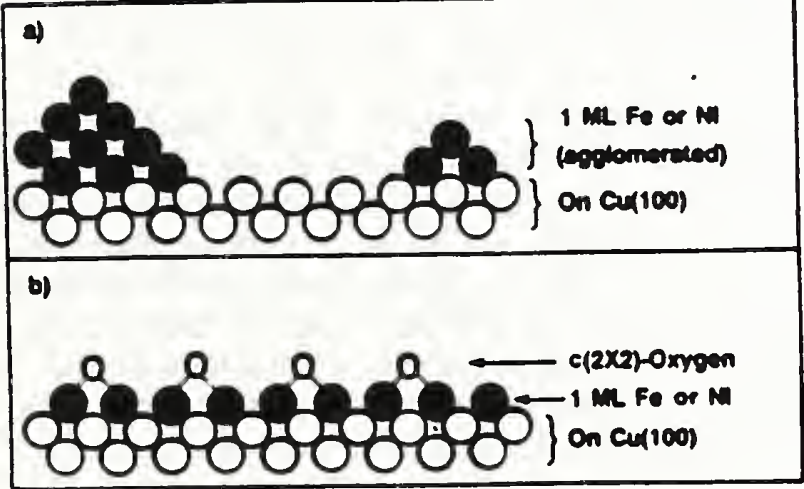

Fig. 2. An illustration of (a) the agglomeration that occurs when $1 \mathrm{ML}$ of $\mathrm{Fe}$ or $\mathrm{Ni}$ is deposited on $\mathrm{Cu}(100)$ around room temperature and (b) how a pre-adsorbed oxygen layer induces the $1-\mathrm{ML} \mathrm{Fe}$ or $\mathrm{Ni}$ to lie flat to maximize its bonding with the oxygen.

Magnetic Properties of Atomically-Engineered Thin-Film Materials

The connection between the structure of epitaxial films and their magnetic properties is currently one of the most intensively investigated topics in the field of magnetism. The reason for this is that such films are expected to lead to new generations of commercial products such as computer discs for information storage and magnetoresistance detectors for disc reading heads. Since these are multi-billion dollar-a-year industries, a worldwide race is on to develop these products which are a key to supremacy in the next generation of information technology.

In attempts to synthesize novel thin-film materials, the critical ingredients for success are determinations of film structure, an understanding of the relationship between structure and properties, and the 
A. Novel Two-Dimensional Materials (W. F. Egelhoff, Jr.)

There exist major gaps in current understanding of the fundamental principles which govern the chemical and physical properties of layered structures in the two-dimensional limit. We plan to synthesize and determine the fundamental properties of ultrathin layered materials with layers so thin (a few atoms thickness) that they exhibit two-dimensional behavior. Knowledge of the factors influencing the growth and properties of ultrathin layered systems is expected to allow optimization of desired chemical and physical characteristics and will thus benefit a number of scientific fields ranging from magnetism to novel semiconductor devices.

Determination of Surface Structure by X-Ray Photoelectron and Auger Electron Diffraction

Over the past several years this project has been developing the technique of $x$-ray photoelectron (XPS) and Auger (AES) forward scattering as a structural probe for the study of surfaces and interfaces. In previous years, the work of this project demonstrated that XPS and AES intensities are strongly enhanced along next-nearest-neighbor axes of a crystal. The angle-resolved XPS and AES spectra thus act like "searchlights" pointing out the bond directions in the top few atomic layers of the sample. As a probe of short-range order, this searchlight effect is very useful for studying the structure of epitaxial films, especially the growth mode in the early stages, and for observing surface segregation and interdiffusion phenomena.

In the past year this technique has been used to investigate the growth of epitaxial films of $\mathrm{Fe}$ on the $\mathrm{Cu}(111)$ surface. It was found that at room temperature and below the $\mathrm{Fe}$ grows in a bcc lattice with the close-packed bcc(110) plane parallel to the close-packed fcc(111) plane of Cu, but with the interface out of registry. Upon annealing this Fe structure above $100^{\circ} \mathrm{C}$, or if the growth temperature is above $100^{\circ} \mathrm{C}$, the $\mathrm{Fe}$ takes an fcc(111) form (pseudomorphic with the $\mathrm{Cu}$ substrate). These results demonstrate how XPS and AES forward scattering allow us to follow in detail the structural transformations that occur in epitaxial films.

One of our plans for the coming year is to investigate how this structural transformation affects the magnetic properties of the $\mathrm{Fe}$. We expect major changes since ultrathin Fe films generally exhibit magnetic properties that are very structure-sensitive.

The Use of Surfactants in Epitaxy

The technique of molecular beam epitaxy holds considerable promise as a source of novel materials and devices. However, to fulfil this promise continuous progress will have to be made in our ability to control, at the atomic level, the exact arrangement of atoms in the epitaxial structure. The use of adsorbed gases as a tool for modifying the structure of epitaxial films has been an occasional topic of investigation in this project for the past four years. The initial results have been rather promising, particularly in the area of trying to induce high-surface-free- 
that it is predictable, with particular attention to semiconductor-metal interfaces.

\section{Grazing Angle X-Ray Diffraction and Surface Roughness}

In collaboration with Dr. D. Novotny of the NIST Semiconductor Electronics Division and Drs. M. B. Bedzyk and Q. Shen of the Cornell High Energy Synchrotron Source, grazing-angle diffraction has been used to study the surface roughness of germanium. A new phenomenon was directly observed--the superficial wave. This is a diffracted wave trapped at an interface where a change occurs in the dielectric susceptibility of the medium. The wave is scattered back out of the interface by roughness. It is potentially more sensitive to roughness than $x$-ray reflectivity measurements because the superficial wave is capable of propagating along the interface for millimeters. Roughness of samples on a scale of a few hundred angstroms was clearly evident, leading to the conclusion that roughness of a scale of ten angstroms or less should be detectable. A kinematical theory of rescattering was combined with the dynamical theory of diffraction to give qualitative understanding of the scattering process.

\section{Back-Reflection X-Ray Standing Waves and Surface Relaxation}

$\mathrm{X}$-ray standing waves (XSW) originating from diffraction can be used to determine adsorbate position with respect to the bulk lattice, as long as the lattice is nearly perfect. When combined with nearest-neighbor distances obtained from measurements of the surface $x$-ray absorption fine structure, the relaxation of the surface atoms in the presence of the adsorbate is obtained. When the bulk crystal has a high density of defects, such as occurs in a metal, the lattice strain may be compensated by going to a Bragg angle of $90^{\circ}$, but an alternative requirement of high energy resolution $(<0.4 \mathrm{eV})$ is imposed. The focused NIST beamline X-24A at the Brookhaven National Synchrotron Light Source satisfies these requirements adequately to observe relaxation of the surface of copper in the presence of adsorbed sulfur and chlorine In the case of chlorine, a relaxation of $0.07 \AA$ was observed, the first such direct measurement. This work was performed in collaboration with Drs. J. R. Patel, D. W. Berreman, F. Sette, P. H. Citrin, and J. E. Rowe of AT\&T Bell Laboratories, Dr. P. L. Cowan of the NIST Quantum Metrology Division, and Mr. B. Karlin of Brookhaven National Laboratory.

Reflection-Electron Microscopy Studies of Surface Diffusion in Thin Films

Reflection electron microscopy was used to study the development of columnar growth in metal films during deposition on amorphous substrates. Dimensions, orientation, and structure were obtained for crystallites which evolved on substrates held at various temperatures during gold vapor deposition. These data, when compared with theoretical calculations for surface free energy, diffusion, nucleation and growth, led to general predictions on the orientation and growth of fcc films, and a possible new mechanism for explaining whisker growth. This work was done in 
ability to control the structure during growth. These three topics are the focus of the present effort in magnetic thin films. In the past few years, major progress has been made in this project in developing XPS and AES forward scattering as a tool for structural determinations. More recently, this work has been combined with measurements of intensity oscillations for reflection high-energy electron diffraction (RHEED) to gain still deeper insights into epitaxial growth modes.

This combination of techniques has allowed improved growth and processing methods to be developed for optimizing the magnetic properties of epitaxial films. During this year, the properties of $\mathrm{Fe}-\mathrm{Cu}$ sandwich structures produced by us using these methods have been investigated in collaboration with groups at Simon Fraser University in Canada and Cambridge University in England. It has been found that the magnetocrystalline anisotropy (a measure of sample quality and a technologically important parameter) is much greater when these sandwich structures are prepared by our methods rather than by the methods used by others in this field. We also have been able to achieve the theoretically predicted high-spin, or high-moment, state of fcc-Fe in these structures. This work thus represents a vindication of our approach of, first, developing methods for studying the structure, second, investigating the relationship between structure and properties, and finally, developing growth and processing techniques to allow us to gain control of the growth morphology to optimize the properties.

Our research plans for the future consist of extending these studies to other systems such as $\mathrm{Co}, \mathrm{Ni}, \mathrm{Mn}$, and $\mathrm{Cr}$ films on substrates such as $\mathrm{Ag}$, $\mathrm{Au}$, and Pt. We hope to install an in situ magnetic probe such as the magneto-optical Kerr effect to get a more rapid turn-around in information on how processing affects magnetic properties. We also plan to use our existing base of expertise to move into the area of magnetoresistance effects in superlattice structures comprised of magnetic and non-magnetic metals. A giant magnetoresistance effect in such samples has been recently discovered and we are well positioned to make important contributions since there is expected to be a strong structure-properties relationship in these materials. We plan to grow epitaxial films of several metals on highperfection silicon or germanium substrates; these films will be characterized by the $\mathrm{x}$-ray standing wave technique (see below) and then used as substrates on which to grow superlattice structures.

B. Structural Analysis of Interfaces ( $T$. Jach)

The objective of this project is to determine accurate positions and distributions of atoms, particularly at interfaces. This information and related data are used to analyze the energetics of solid surfaces in order to understand and predict epitaxy, reconstructions, and related interface phenomena. Emphasis is placed on the development of techniques using $x$-ray diffraction and reflection at the interfaces, and which look at the deexcitation spectra of the atoms involved. The experiments require intense focussed or collimated x-ray beams available only at synchrotron light sources. A goal is to study and control interface formation to the point 
collaboration with Dr. G. Hembree of Arizona State University and Dr. L. B. Holdeman of COMSAT, Inc.

Future work in this project will concentrate on XSW measurements of atomic positions and point defects at interfaces when metal films are deposited on high-perfection semiconductor substrates. This work will contribute to the project on magnetic properties of superlattice structures described above.

\section{Ballistic Transport Through Interfaces (M. D. Stiles)}

Recent developments in growth capabilities of layered materials make possible the use of abrupt, coherent interfaces to make novel devices. To predict the behavior of such devices it is necessary to understand how electrons transmit from one material to another through these sharp interfaces. In collaboration with Dr. D. R. Hamann of AT\&T Bell Laboratories, a method has been developed for calculating transmission probabilities for abrupt coherent interfaces between arbitrary materials. The method is based on first-principles electronic-structure calculations so that it is only necessary to know the geometry of the interface to predict the transmission probability.

This past year we completed the first calculation using this method for an interface of technical interest. Nickel disilicide is a metal that has a lattice constant very close to that of silicon so that even though the crystal structures are quite different they can be grown on top of each other with highly ideal interfaces. These ideal interfaces have led to a proposed metal-base transistor using nickel disilicide as the base between silicon. For the device to be useful it is necessary that the transmission probability for electrons scattering from the interfaces should be high. Using the method mentioned above we found that the transmission probability is too low for the proposed device to work as hoped. In addition we found that there is a large difference in the transmission probability for the two possible interfaces that will form depending on the growth kinetics. This prediction should make it possible to test the method we have developed.

We are currently working to extend the method so that it is capable of treating III-V compound semiconductors. The modifications are of a technical nature and not in the basic method itself. We will apply this method to proposed devices that rely on highly ideal interfaces between the different semiconductors, in particular those that make use of tunneling though narrow layers of these semiconductors. In addition we will apply this method to interfaces between III-V semiconductors and group IIItransition metal bimetallic systems that are being studied for use in novel devices.

D. Micro-Structural and Micro-Compositional Characterization of Novel

Materials (A. J. Melmed, P. P. Camus, and H. B. Elswijk*)

The techniques of field-ion microscopy (FIM) and atom-probe (AP) mass analysis can be applied to a wide range of novel materials to give real- 
space determinations of surface structure and qualitative bulk atomic structure, information that is complementry to results from other microscopies and diffraction techniques. The unique capability of specimen dissection by controlled field evaporation enables elemental composition determinations to be made with sub-nanometer spatial resolution. These techniques have been used for micro-structural and micro-compositional characterization of two types of novel materials, high-temperature superconductors and magnetic thin films.

High- $T_{c}$ Superconductors (A. J. Melmed, P. P. Camus, and H. B. Elswijk*)

The superconducting critical temperature, $T_{c}$, is highly dependent upon the oxygen concentration in the 1-2-3 ceramic oxide materials. Because the most oxygenated material is not a stable compound, oxygen out-diffusion may occur, thereby modifying the electrical properties, especially in the nearsurface region. This possibility has significant implications, especially for the interpretation of data obtained with surface-sensitive techniques. Therefore, the effect of vacuum exposure on the near-surface composition of ceramic superconductors was studied. Based upon the number of detected ions per surface layer, it was determined that the only type of atom probe capable of measuring statistically significant differences in the surface composition was a wide-angle atom probe with which circular regions of diameter typically $170 \AA$ can be examined.

Atom-probe field-ion microscopy specimens were fabricated from Eu 1-2-3 superconducting material using the method of sharp shards. Initial surface composition measurements after imaging showed a non-stoichiometric, oxygendepleted layer. A "deep-cleaning" procedure was then employed whereby field evaporation was used to remove approximately 5-10 $\mathrm{nm}$ of material. Subsequent composition analyses confirmed that this treatment was sufficient to remove the non-stoichiometric layer and to reveal a surface consisting of the expected 1-2-3-7 material. Various vacuum exposures at $85 \mathrm{~K}$ and room temperature were performed followed by composition analyses of the near-surface region.

For vacuum treatments of three hours at $85 \mathrm{~K}$, no measurable change in the oxygen or metallic content was observed. For vacuum treatments of approximately 18 hours at room temperature, no change was measured in the metallic contents; however, a significant change was observed for the oxygen content. These results indicate that data obtained from freshly cleaved samples at or below $85 \mathrm{~K}$ by surface analysis techniques should be characteristic of material consisting of the expected composition, in contrast to samples exposed for longer periods of time at room temperature. $\mathrm{T} \ell$-based ceramic superconductors were also analyzed in an attempt to determine changes in the oxygen concentration in the near-surface region. However, the material was found to be too inhomogeneous in composition for reliable measurements.

Investigations of the diffusivity of electrical-contact metals ( $\mathrm{Au}, \mathrm{Ag}$, etc.) into ceramic superconductors are planned. It is hoped that the results will lead to a better understanding of the mechanical strength and interdiffusion properties of metal/superconductor contacts. 
Magnetic Thin Films (P. P. Camus and A. J. Melmed)

Unique magnetic properties are obtained from composite thin films consisting of non-magnetic and magnetic components, $\mathrm{Ag}$ and $\mathrm{Fe}_{3} \mathrm{O}_{4}$ for instance. Mossbauer spectroscopy indicated that the magnetic contributions are a function of the Ag content, diffraction studies identified the phases as pure $\mathrm{Ag}$ and pure $\mathrm{Fe}_{3} \mathrm{O}_{4}$ particles, and transmission electron microscopy (TEM) determined the particle size to be in the range $3-30 \mathrm{~nm}$ (as a function of $\mathrm{Ag}$ content). But the chemical distributions of the elements have not been obtained. Therefore, a study was commenced whereby the field ion microscope was used to observe the microstructure and atom-probe microanalysis was used to measure the distribution and concentration of the elements.

The TEM studies indicated that conventional specimen preparation techniques produced artifacts; therefore, the method of sharp shards was used for specimen fabrication. The electrical conductivity of the thin films, which consist of a large volume fraction of $\mathrm{Fe}_{3} \mathrm{O}_{4}$, could be expected to be dominated by the (at best) semi-conducting properties of the $\mathrm{Fe}_{3} \mathrm{O}_{4}$. As FIM requires a finite conductivity at $85 \mathrm{~K}$, a success at imaging the material was not guaranteed. However, it was found that field-ion images and AP analyses could be obtained. Brightly imaging regions in a dimly imaging matrix indicative of particles and dark regions indicative of voids were observed. AP analyses were more difficult than for metals or ceramic superconductors. The preliminary results indicate that the $\mathrm{Ag}$ is not homogeneously distributed, but there exist Ag-enriched and Ag-depleted regions, which is consistent with the previous studies.

The current plan is to extend the work by characterizing the composition of the brightly imaging regions and the matrix, and by quantifying the extent and amplitude of the Ag-enriched regions in a few of the available sample compositions. It is hoped that a better understanding of the effect of the Ag on the microstructure will be useful in optimizing the commercially important magnetic properties of these composite thin films. This work has been performed in collaboration with Dr. R. D. Shull of the NIST Metallurgy Division.

Simulation of Field-Ion Microscope Images for Icosahedral Materials (A. J. Melmed and H. B. Elswijk*)

A complete description of the atomic structure for the icosaehdral phase of Al-Mn has not yet been found and, in fact, there is still no general consensus on the most appropriate structural model to describe the phase. Accordingly, new models have been explored with regard to their agreement with the various experimental observations. The results of computer simulations, using the new structural models, with field ion microscopy observations have been compared.

The overall visual appearance of the experimental FIM images was best matched by a model having a large cubic unit cell ( $3.32 \mathrm{~nm}$ ) containing a Mackay icosahedral motif. This interesting result clearly indicates that, 
for a unit cell which is large on the scale of the FIM specimen, the dominant symmetry features of the FIM image are due to the internal atomic motif (icosahedral) of the unit cell rather than to the crystal symmetry (cubic).

\section{SURFACE SPECTROSCOPIES AND STANDARDS GROUP}

Many different spectroscopies are used for the characterization of surfaces. Emphasis is placed here on the development of a conceptual understanding of important emerging spectroscopies and results, on the provision of needed information and data for widely used spectroscopies and related techniques, the development of new surface-characterization methods, the development of needed standard reference materials, and involvement with national and international standards committees concerned with surface analysis.

A. Theory of Dynamical Molecular Processes at Surfaces (J.W. Gadzuk and E. Blaisten-Barojas ${ }^{\star}$ )

This project is part of a continuing effort directed to understanding both the static and dynamic behavior of atoms, molecules, solids, surfaces, radiation and their mutual interactions. This understanding comes from consideration of the microscopic atomic-scale statistical properties of ensembles. Based upon our studies, phenomenological model theories and numerical simulations are constructed which relate to the chemical physics and statistical-mechanical behavior and to the intrinsic properties of relevant physico-chemical systems. In addition, a significant effort is invested in the study of the role of an actual measurement process in determining observed quantities in different surface spectroscopies. Ways in which measurement-process-specific quantities such as line shapes, satellite structures, etc. provide additional information on system dynamics are of considerable interest.

\section{Resonance-Assisted Electron-Stimulated Desorption (J.W. Gadzuk)}

Recent experiments have shown giant enhancements in the stimulated desorption of adsorbates from a surface under bombardment by electrons of a certain energy. These enhancements appear to be due to the electron being trapped in a temporary negative-ion shape resonance. In collaboration with Dr. C. W. Clark of the NIST Radiation Physics Division, a theory has been developed for the resonance enhancement in terms of time-dependent wavepacket propagation. This theory accounts for the large resonanceenhanced desorption yields observed for oxygen adsorbed on palladium surfaces.

Vibrational Relaxation of Molecules on Finite Metal Clusters ( $\mathrm{J}$. W. Gadzuk and E. Blaisten-Barojas")

Picosecond pump-probe experiments are being carried out (see section 2.A) to determine the vibrational relaxation times associated with intramolecular vibrationally excited states of diatomic molecules adsorbed on 
metal surfaces. For experimental reasons, the initial measurements have been made with small metal clusters, thus opening up the possibility that finite quantum-size effects could influence the vibrational relaxation rate due to cluster electron-hole pairs and thus the measured absorption spectrum or lineshape. We have developed an exactly solvable theory for such relaxation and lineshapes in which the cluster electron-gas is treated within the random-phase approximation. The resulting absorption lineshapes are extremely cluster-size dependent when the cluster size increases from

$\sim 5$ to $\gg 50 \AA$, as illustrated in Fig. 3. Due to quantum-size effects, the absorption spectrum is a series of sharp delta functions clothed in a Lorentzian-type envelope whose width is the inverse of the measured vibrational relaxation time. The spacing of the delta functions varies inversely with cluster size. In this way, such measurements may also be useful diagnostic probes of cluster properties.

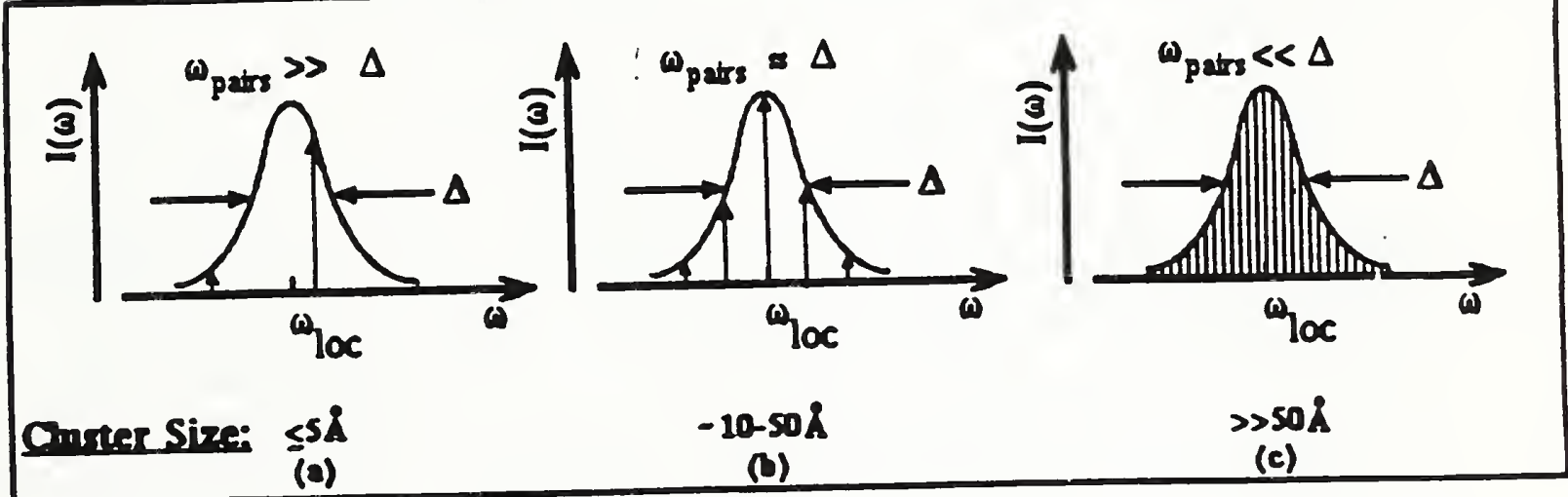

Fig. 3. Model absorption spectra for localized oscillator on metallic cluster of varying characteristic dimension and thus electron-hole pair excitation energy, as labelled.

Chaos and Fractals in Molecule-Surface Collisions (J. W. Gadzuk)

In collaboration with $\mathrm{Dr}$. N. Sathyamurthy of the Indian Institute of Technology, numerical simulations of molecule-surface scattering events have shown two qualitatively different classes of behavior. One class exhibits simple and smooth scattering characteristics such as translational to internal-state energy redistribution while the other shows the formation of long-lived trapped-molecule-surface resonances. Under some circumstances, the energy redistribution patterns of these resonances displayed a self-similarity indicative of an inherent fractal structure within the dynamics. We have been the first to note and study such behavior, within the context of non-linear chaotic dynamics at surfaces. We have also succeeded in quantifying earlier apparent random results, thus opening the door to a new approach to analysis of numerical surface dynamics. 
We plan to continue work in the area of surface reaction dynamics with near-term emphasis on the determination of self-consistent reaction trajectories, and the determination of energy-redistribution patterns amongst translational, vibrational, rotational, and electronic degrees of freedom of "reactant" molecules and electron and phonon modes of surfaces. Analyses are made for controllable dynamic and reactive conditions with synthesis of the various components of the elementary reaction theories into theories of experimentally realizable processes. Special emphasis will be placed on the phenomenon of dissociative surface processes and on the role of non-linear dynamics. In addition, analysis will be made, whenever possible, of novel experimental results. Current interest includes laser-assisted surface processes and state-to-state analysis, high-resolution surface vibrational spectroscopy, picosecond pump-probe studies of molecular vibrational relaxation times in the presence of small metal clusters showing quantum-size effects, and other experimental probes of non-adiabatic effects.

B. Ion-Surface Interactions (J. Fine, G. P. Chambers," D. Marton," M. H. Mintz" and M. H. Shapiro")

Ion beams are used to bombard surfaces in order to measure surface composition (e.g., by secondary-ion mass spectrometry or ion-scattering spectroscopy) and to remove surface layers so that the composition of the exposed surface can be measured as a function of depth (i.e., a depth profile). Many physical phenomena occur during ion bombardment that are poorly understood, amongst them the nature of excitation events during the collision cascade, the energy states of ejected ions and neutrals, and ioninduced effects such as diffusion or segregation. Much of the available literature describes the ion-surface interactions in macroscopic terms such as the sputtering yield but these is a growing need for fundamental understanding at the microscopic level. In addition, there are needs for evaluated sputtering yield data, for standard reference materials to allow convenient determination of sputter-removal rates and other purposes, and for characterization of the changing topography of ion-bombarded surfaces.

Laser Spectroscopy of Sputtered Atoms and Ions (J. Fine and M. H. Mintz*)

In collaboration with Dr. J. D. Fassett of the NIST Inorganic Analytical Research Division, a series of experiments has been designed to determine the kinetic energy distributions of specific sputtered atoms and ions and their states of excitations. Resonance multiphoton laserionization schemes have been developed to detect sputtered atoms in specific excited states.

Measurements have been recently made of the kinetic energy distributions of collisionally ejected ions and neutrals from polycrystalline $\mathrm{Mg}$ by $3 \mathrm{keV}$ argon ions. The measured $\mathrm{Mg}^{+} \mathrm{KE}$ distributions depend on extraction potential and indicate for our time-of-flight analyzer that the ion angular distributions are energy dependent. At higher energies ( $30-100 \mathrm{eV}$ ), the angular distributions are less cosine-like (more forward peaked) and more shifted to the specular direction. A one-color 
$(285.2 \mathrm{~nm})$, two-photon ionization scheme has been used to detect $\mathrm{Mg}^{\circ}$. The $\mathrm{Mg}^{\circ} \mathrm{KE}$ distributions show an enhanced number of high-energy neutrals for our $55^{\circ}$ angle of incidence compared to what would be expected for a normalincidence ion beam.

We are currently developing a laser ionization scheme to detect collisionally excited $\mathrm{Mg}^{\circ}$ in the $3 \mathrm{~s} 3 \mathrm{p}$ metastable state and to determine its $\mathrm{KE}$ distribution. Following that, we plan to investigate the $\mathrm{KE}$ distributions and state populations of sputtered $\mathrm{Mg}^{+}$by means of ultraviolet two-color resonance methods.

Detection of Atom Vaporization from Solid Surfaces by Laser Resonance Ionization ( $J$. Fine and M. H. Mintz*)

Many surface growth mechanisms and the manner in which they evolve are often difficult to characterize. One possible way to monitor the coveragedependent development of processes that affect surface-atom vaporization is to actually measure the change in the surface vapor pressure. We have used the single-atom detection capability of resonant multiphoton ionization techniques to observe directly the vaporization of $\mathrm{Mg}$ atoms from a partially oxidized polycrystalline Mg surface. By investigating the submonolayer oxidation regime, we have been able to show that two different chemisorption mechanisms can be experimentally distinguished: an initial random chemisorption stage followed by an island growth stage that dominates this process.

The possibility for the direct detection of changes in atom vaporization from surfaces that have low vapor pressures ( $10^{-17}$ Torr) suggests that this type of measurement could have application to the study of a variety of surface processes involving both single and multiphase systems - many of which were previously not considered experimentally feasible. Examples of such process in addition to chemisorption include monolayer film growth modes, interdiffusion at sputter-profiled interfaces, and surface segregation.

\section{Simulation of Ion-Surface Collisions (M. H. Shapiro* and J. Fine)}

Multiple-interaction calculations have been performed to simulate ionsurface collisions occurring for typical sputtered conditions and to investigate the dynamical phenomena occurring in the resulting collision cascades. We have been particularly interested in investigating collisional-ion/surface-excitation processes which lead to the ejection of excited atoms from single-crystal solids. This past year we have completed an analysis of multiple-interaction calculations for $5 \mathrm{keV} \mathrm{Ar}^{+}$collisions with Al. Collisional mechanisms, trajectories, and their dependence on atom geometry in the target have been explored. In contrast to most previous studies, we find that essentially all ejection of core-excited atoms results from asymmetric collisions (an incident ion colliding with a target atom). Analysis of the trajectories indicates that the excitation/ejection collision can be of two general types, depending on whether the incident ion is coming in along a low- or a high-index direction. We have just begun to make a computer movie of these 
trajectories and of the excitation/ejection encounters so that these results can be more effectively explained and understood. Our calculations also agree very nicely with measurements of the azimuthal dependence of the bombarding ions on the Auger-electron de-excitation of atoms sputtered from Al(100) performed recently in collaboration with scientists at the Centre d'Etudes Nucleaires, Saclay, France.

\section{Sputtering-Induced Surface Microroughness (J. Fine and D. Marton*)}

Changes in surface microtopography which often occur during ion bombardment can significantly affect the measured depth resolution of interfaces in sputter depth profiles. To better understand the importance of this roughening effect on interface analysis, we have developed a new type of microscope, the Scanning Scattering Microscope (SSM), for which a patent application is being filed.

The SSM makes use of a finely focused laser beam (632 nm) to scan the surface being examined. Almost all of the non-specularly reflected light is collected with a hemispherical mirror to give a roughness image of the surface as the laser beam is scanned. The light signal is determined by the local roughness of the surface, not by the shape or changes of height that other methods provide. We have evaluated the SSM by examining a number of test specimens: sputter-profiled thin-film interfaces, an integrated circuit linewidth test pattern, NIST SRM 475 optical microscopy standard, and a polished silicon surface. We find that the SSM can give a quantitative measurement of rms surface roughness (for roughness less than $100 \mathrm{~nm}$ ) and a height sensitivity of about $1 \mathrm{~nm}$. We also find that the surface roughness of ion-bombarded $\mathrm{Ni} / \mathrm{Cr}$ and $\mathrm{Ag} / \mathrm{Ni}$ thin-film systems correlate with depth-resolution (interface-width) measurements on the same specimens by Auger depth profiling.

Compilation of Ion Sputtering Yield Data (J. Fine and G. P. Chambers*)

We are preparing a compilation of evaluated sputtering-yield data for those parameters that will have specific use in surface analys is and depth profiling. Our compilation will be in tabular form for those ion species ( $\mathrm{Ne}, \mathrm{Ar}, \mathrm{Kr}, \mathrm{Xe}, \mathrm{O}_{2}, \mathrm{~N}_{2} . \mathrm{Cs}$ ) and energies ( 0.5 to $20 \mathrm{keV}$ ) and angles of incidence used in surface characterization. The compilation will contain sputtering yields for elemental targets only.

Sputtering yield data have been evaluated using a method based on target surface reactivity, surface oxide formation, and sputter removal rates. Limits were established for determining which data were more consistent than others. Based on the setting of such limits and on the total ion dose used to obtain the measurement, we have been able to show that subsets of the yield data exist which are quite reasonable in the scatter of the data and which have the expected dependence on ion energy. We have also found the preferred yield data could be fitted to curves generated from the Sigmund sputtering theory and Ziegler-Biersack-Lindhard nuclear stopping cross sections. These fitted curves will be used to generate recommended values of sputtering yields for ion energies from 0.5 to $20 \mathrm{keV}$. We anticipate that our evaluated yield data (recommended 
values) will be much more useful and reliable than the unevaluated data compilations that are now available. This work is supported by the NIST Office of Standard Reference Data.

Development and Production of Standard Reference Materials for SputterDepth Profiling (J. Fine and D. Marton*)

Standard reference materials (SRMs) are needed for the convenient determination of ion-beam sputter-removal rates, for optimization of ionsputtering conditions to achieve high depth resolution, for calibration of surface analysis instrumentation, and related functions. Our development of SRMs has been supported by the NIST Office of Standard Reference Materials.

\section{(i) NIST SRM 2135}

We have previously developed, fabricated, and certified SRM 2135, a multilayered $\mathrm{Ni} / \mathrm{Cr}$ thin-film structure for calibrating sputter depths and erosion rates, for monitoring ion beam stability, and for optimizing sputtering conditions. The total sales of SRM 2135 is now more than 160 but the stock has been depleted. Work is now in progress on the fabrication of a large additional stock (600-900 pieces) of SRM 2135. Because the fabrication facility used previously is no longer available, we are developing new fabrication techniques at the Comsat Laboratories in Germantown, MD. Using rf planar-magnetron sputter-deposition techniques, prototype materials have been developed with properties very similar to those of the previous SRM 2135. These properties include sharpness of interfaces, film-thickness uniformity from sample-to-sample, and layerthickness uniformity from layer to layer. We believe that the uncertainty in all layer thicknesses can be kept to \pm 28 . Production of stock is now proceeding.

\section{(ii) NIST SRM 2136}

A new "marker-type" SRM has been under development along with improved Auger profiling techniques necessary for its characterization. This $\mathrm{Cr} / \mathrm{Cr}_{2} \mathrm{O}_{3}$ multilayered thin-film structure consists of 7 well-defined, thin oxide-marker layers (about 3 monolayers thick) separated by $\mathrm{Cr}$ films which are about $30 \mathrm{~nm}$ thick. The uniformity of the marker layer spacing is about 38 (one standard deviation); it should be very useful both as a depth profile standard for secondary-ion mass spectrometry analysis as well as a sensitivity standard for Auger analysis. The new SRM has been certified for total $\mathrm{Cr}$ thickness by differential pulse polarography and inductively coupled plasma spectroscopy. This total $\mathrm{Cr}$ thickness is $175.3 \pm 6.4 \mu \mathrm{g} / \mathrm{cm}^{2}$ where the uncertainty corresponds to two standard deviations. The individual $\mathrm{Cr}$ layer thicknesses have been certified from the total $\mathrm{Cr}$ thickness and from Auger sputter-depth-profile measurements. 
(iii) New SRM for the Calibration of Energy Scales of Auger-Electron and X-Ray Photoelectron Spectrometers

We are developing a new SRM consisting of $\mathrm{Cu}, \mathrm{Ag}, \mathrm{Au}$, and $\mathrm{Si}$ for the convenient calibration of the energy scales of Auger-electron and $x$-ray photoelectron spectrometers. Prototype single-element specimens have been fabricated by rf planar-magnetron sputter deposition; work is proceeding on their evaluation for diffraction effects.

C. Electron Spectroscopy of Surfaces (C. J. Powell, N. E. Erickson, and S. M. Thurgate*)

Electron-spectroscopic techniques are extensively used for different types of surface characterization, particularly to attain surface sensitivity. Two techniques, Auger-electron spectroscopy (AES) and $x$-ray photoelectron spectroscopy (XPS), are in widespread use for measurements of surface composition. The objective of this project is to provide needed reference data to enhance the utility of the techniques in common use.

Inelastic Mean Free Paths of Low-Energy Electrons in Solids (C. J. Powe 11)

Values of inelastic mean free paths (IMFPs) of low-energy $(\approx 50-2000$ eV) electrons are needed for quantitative surface analyses by AES and XPS. Information is particularly desired on the dependences of the IMFP on material and electron energy.

In a collaboration with Drs. D. R. Penn of the NIST Electron Physics Group and S. Tanuma of the Nippon Mining Company, calculations have been made of IMFPs for $200-2000 \mathrm{eV}$ electrons in 27 elemental solids and 4 compounds. From these IMFP values, we developed a general formula to predict IMFPs for other materials in terms of several material parameters. We have now extended the calculations to lower energies by avoiding an approximation in the algorithm used previously. Substantial differences are found in the shapes of the IMFP versus energy curves in the $10-200 \mathrm{eV}$ range for different materials. Figure 4 shows examples of these curves for aluminum and gold which are illustrative of the data for free-electron-like and non-free-electron-like materials, respectively. The minimum IMFP value is found about $40 \mathrm{eV}$ for $\mathrm{Al}$ while that for $\mathrm{Au}$ occurs at $120 \mathrm{eV}$. These differences can be understood in terms of the different inelastic scattering mechanisms in the two metals. The differences in the shapes of the IMFP-energy curves at low energies also indicate a serious limitation in the widely used formula of Seah and Dench for a related quantity, the electron attenuation length. We have found that our IMFP results could be adequately represented by a modified form of the Bethe equation over the 50-2000 eV range; this new formula should be a useful means of predicting the IMFP dependences on material and energy. We are currently extending the IMFP calculations to other materials for which optical constants (needed typically over a range of about 1-1000 eV) are available. 


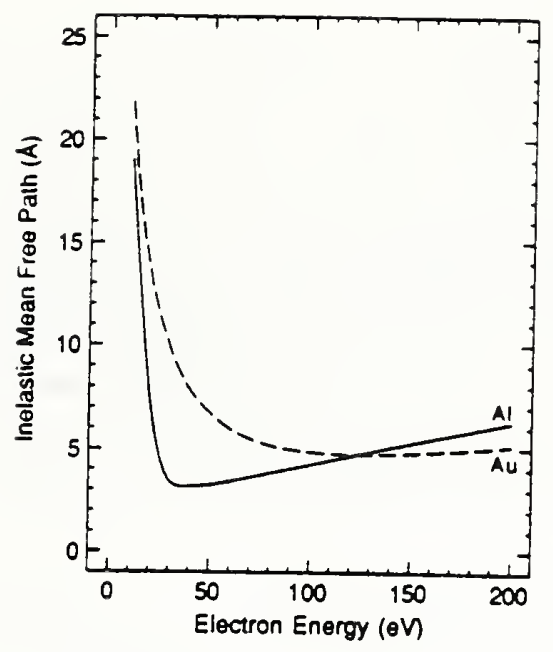

Fig. 4. Plots of the calculated inelastic mean free paths for aluminum (solid line) and gold (dashed line) as a function of electron energy.

Uncertainties in Quantitative Surface Analyses by AES and XPS (C. J. Powe 11)

In a collaboration with Dr. M. P. Seah of the UK National Physical Laboratory, an extensive review has been made of the individual steps in AES and XPS analyses and of the various sources of uncertainty for each step. Quantitative analyses are difficult to perform on account of the many options available and the morphological complexity of many specimens, lack of adequate knowledge of instrumental performance, and to limitations of current methodology and data. While there are many pitfalls, there has been substantial progress in recent years in recognizing the more serious problems and in providing solutions, procedure, and data. It is believed that the review will be a useful source of guidance for the many users of $\mathrm{AES}$ and XPS instruments.

Characterization of Oxide Layers on InP (N. E. Erickson and S. M. Thurgate*)

Indium phosphide is an important compound semiconductor yet little is known of its surface composition after different preparation procedures. One of the difficulties in the use of a technique such as XPS coupled with argon-ion bombardement to get composition information as a function of depth is that the ion bombardment can modify the chemical compounds present.

We have measured XPS data for InP samples prepared in different ways as a function of ion bombardment time. From an analysis of the "chemical" shifts of the core-electron lines and of changes of lineshapes, we have been able to deduce the nature of the initial oxide surface and the changes in composition with depth for the different samples. 
D. Surface-Analysis Standards Committees (C. J. Powell and J. Fine)

The Division is active in ASTM Committee E-42 on Surface Analysis and with two international groups, the Surface Chemical Analysis Technical Working Party of the Versailles Project on Advanced Materials and Standards (VAMAS) and the Subcommittee on Surface Analysis of the International Union of Pure and Applied Chemistry (IUPAC). These groups provide reference procedures, needed reference data, and characterization of reference materials for the techniques of surface analysis in common use. The groups also sponsor symposia and workshops and conduct laboratory intercomparisons of particular types of measurements. 


\section{PUBLICATIONS}

A. Publications of Past Fiscal Year

Beckerle, J. D., Casassa, M. P., Cavanagh R. R., Heilweil, E. J., and Stephenson, J. C., "Time Resolved Studies of Vibrational Relaxation Dynamics of $\mathrm{CO}(\mathrm{v}=1)$ on Metal Particle Surfaces," J. Chem. Phys. 90 , 4619 (1989).

Buntin, S. A., Richter, L. J., Cavanagh, R. R., and King, D. S., "Optically Driven Surface Reactions: Evidence for the Role of Hot Electrons," Phys. Rev. Lett. 61, 1321 (1988).

Burgess, Jr., D. R. F., Cavanagh, R. R., and King, D. S., "NO/NH Coadsorption on Pt(111): Kinetic and Dynamical Effects in Rotational Accommodation," Surface Sci. 214, 358 (1989).

Cowan, P. L., Brennan, S., Jach, T., and Lindle, D. W., "Performance of a High Energy Resolution, Tender X-Ray Synchrotron Radiation Beamline," Rev. Sci. Instrum. 60, 1603 (1989).

Demmin, R. A. and Madey, T. E., "The Interaction of Oxygen and Platinum on W(110)," J. Vac. Sci. Tech. A I, 1954 (1989).

Demmin, R. A., Shivaprasad, S. M., and Madey, T. E., "Adsorption Properties of Pt Films on W(110)," Langmuir 4, 1104 (1988).

Dutcher, J. R., Cochran, J. F., Jacob, I., and Egelhoff, Jr., W. F., "Brillouin Light Scattering Intensities for Thin Magnetic Films with Large Perpendicular Anisotropies," Phys. Rev. B 39,10430 (1989).

Egelhoff, Jr., W. F., "X-Ray Photoelectron Forward Scattering Studies of Surface Segregation in Epitaxial $\mathrm{Ni}-\mathrm{Cu}-\mathrm{Ni}(100)$ Sandwich Structures," J. Vac. Sci. Tech. A I, 2060 (1989).

Egelhoff, Jr., W. F., and Jacob, I., "RHEED Oscillations at 77K," Phys. Rev. Lett. 62, 621 (1988).

Egelhoff, Jr., W. F., and Steigerwald, D. A., "The Role of Adsorbed Gases in Metal on Metal Epitaxy," J. Vac. Sci. Tech. A I, 2167 (1989).

Elswijk, H. B., Melmed, A. J., and Fowler, H. A., "On the Interpretation of Field Ion Microscopy (FIM) Images of Asymmetrical Specimens of "1,2,3"Type High- $T_{c}$ Superconductors," J. de Physique 49, C6-489 (1988).

Ernst, N., Bozdech, G., and Melmed, A. J., "Combined Field Ion and Field Electron Emission Microscopy of $\mathrm{YBa}_{2} \mathrm{Cu}_{3} \mathrm{O}_{7-\mathrm{x}}, " \mathrm{~J}$. de Physique 49 , C6-453 (1988). 
Gadzuk, J. W., "Soluble Models in Surface Collision Dynamics," Solvay Conference on Surface Science, F. W. de Wette, ed., (Springer-Verlag, $1988)$ p. 310.

Gadzuk, J. W., "The Semiclassical Way to Molecular Dynamics at Surfaces," Ann. Rev. Phys. Chem. 39,395 (1988).

Grant, J. T., Williams, P., Fine, J., and Powell, C. J., "The Status of Reference Data, Reference Materials, and Reference Procedures in Surface Analysis," Surf. Interface Anal. 13, 46 (1988).

Heilweil, E. J., Cavanagh, R. R., and Stephenson, J. C., "Picosecond Study of the Population Lifetime of $\mathrm{CO}(\mathrm{v}=1)$ Chemisorbed on $\mathrm{SiO}_{2}$-Supported Rhodium Particles," J. Chem. Phys. 89, 5342 (1988).

Heilweil, E. J., Stephenson, J. C., and Cavanagh, R. R., "Measurements of $C O(v=1)$ Population Lifetimes: Metal-Carbonyl Cluster Compounds Supported on $\mathrm{SiO}_{2}$," J. Phys. Chem. 92, 6099 (1988).

Himpsel, F. J., McFeely, F. R., Taleb-Ibrahimi, A., Yarmoff, J. A., and Hollinger, G., "Microscopic Structure of the $\mathrm{SiO}_{2} / \mathrm{Si}$ Interface," The Physics and Chemistry of $\mathrm{SiO}_{2}$ and the $\mathrm{Si}_{-} \mathrm{SiO}_{2}$ Interface, R. Helms and B. E. Deal, eds. (Plenum Publishing Corporation, 1988), p. 219.

Hoffman, A., Guo, X., Yates, Jr., J. T., Gadzuk, J. W., and Clark, C. W., "Electron-Stimulated Desorption and Surface Species Conversion: Oxygen on the Pd(111) Surface," J. Chem. Phys. 90, 5793 (1989).

Jach, T., Cowan, P. L., Shen, Q., and Bedzyk, M. J., "Dynamical Diffraction of X-Rays at Grazing Angle," Phys. Rev. B 39,5739 (1989).

Johnson, A. L., Joyce, S. A., and Madey, T. E., "Electron Stimulated Desorption Ion Angular Distributions (ESDIAD) of Negative Ions," Phys. Rev. Lett. $\underline{61}, 2578$ (1988).

Joyce, S. A., Johnson, A. L., and Madey, T. E., "Methodology for Electron Stimulated Desorption Ion Angular Distributions (ESDIAD) of Negative Ions," J. Vac. Sci. Tech. A I, 2221 (1989).

Joyce, S. A., Yarmoff, J. A., Madey, T. E., and Johnson, A. L., "Chemisorption of HF on Silicon Surfaces," Chemical Perspectives of Electronic Materials, M. E. Gross, J. T. Yates, Jr., and J. Jasinski, eds. (Materials Research Society Symposium Proceedings, Pittsburgh, 1989) p. 185.

King, D. S. and Cavanagh, R. R., "Molecular Desorption from Solid Surfaces: Laser Diagnostics and Chemical Dynamics," Advances in Chemical Physics, K. P. Lawley, ed., (John Wiley \& Sons, Ltd. 1989) p. 45. 
Kurtz, R. L., Robey, S. W., Stockbauer, R. L., Mueller, D. R., Shih, A., and Toth, L., "Resonant Excitation of an Oxygen Valence Satellite in Photoemission from High- $\mathrm{T}_{c}$ Superconductors," Phys. Rev. B 39, 4768 (1989).

Kurtz, R. L., Stockbauer, R. L., Mueller, D. R., Shih, A., Toth, L., Osofsky, M., and Wolf, S., "Initial Stages of Degradation of Superconductor Surfaces: $\mathrm{O}_{2}, \mathrm{H}_{2} \mathrm{O}, \mathrm{CO}_{2}$, and $\mathrm{O}_{2}, "$ Phys. Rev. B $\underline{37}, 7936$ (1988).

Kurtz, R. L., Stockbauer, R., Madey, T. E., Roman, E., and de Segovia, J. L., "Synchrotron Radiation Studies of $\mathrm{H}_{2} \mathrm{O}$ Adsorption on $\mathrm{TiO}_{2}(110)$," Surface Sci. 218, 178 (1989).

Lindle, D. W., Cowan, P. L., Jach, T., and Deslattes, R. D., "Polarized XRay Emission Spectroscopy," Nucl. Instr. \& Meth. B 40/41, 257 (1989).

Lindle, D. W., Cowan, P. L., LaVilla, R. E., Jach, T., Deslattes, R. D., Perera, R. C. C., and Karlin, B., "Near-Threshold X-Ray Fluorescence Spectroscopy of Molecules," Proc. of the SPIE 911, 54 (1988).

Lince, J. R., Stewart, T. B., Hills, M. M., Fleishchauer, P. D., Yarmoff, J. A., and Taleb-Ibrahimi, A., "The Chemical Interaction of Mn with the $\mathrm{MoS}_{2}(0001)$ Surface Studied by High-Resolution Photoelectron Spectroscopy," J. Vac. Sci. Tech. A I, 2469 (1989).

Madey, T. E., Johnson, A. L., and Joyce, S. A., "Electron and Photon Stimulated Desorption: Benefits and Difficulties," Vacuum 38,579 1988).

Marton, D. and Fine, J., "In-Situ Surface Roughness Measurement During Sputter-Depth Profiling," Proceedings of Symposium on the Physics of Ionized Gases, Sarajevo, Yugoslavia (1988) p. 228.

Marton, D., Fine, J., and Chambers, G. P., "Temperature-Dependent Radiation-Enhanced Diffusion in Ion-Bombarded Solids," Phys. Rev. Lett. 61, 2697 (1988).

Melmed, A. J., "A Method of FIM-FEEM Specimen Preparation of Superconducting and Other Oxides," J. de Physique 49, C6-67 (1988).

Melmed, A. J. and Shinn, N. D., "Nucleation and Growth of $\mathrm{Cr}$ on Stepped Surfaces with Facets - An FEEM Study," J. de Physique 48, C6-33 (1987).

Melmed, A. J., Shull, R. D., and Chiang, C. K., "Progress in Field Ion Microscopy Imaging of High- $\mathrm{T}_{\mathrm{c}}$ Superconducting Oxides," J. de Physique 49, C6-459 (1988).

Melmed, A. J., Shull, R. D., Chiang, C. K., and Fowler, H. A., "The Atomic Fingerprint of $\mathrm{YBa}_{2} \mathrm{Cu}_{3} \mathrm{O}_{7-x}$ Type High-Temperature Superconductors Observed by Field Ion Microscopy," J. Mat. Sci. Eng. 100, L27 (1988). 
Miller, M. K., Melmed, A. J., and More, K. L., "An APFIM/FEM Investigation of Planar Defects in High Temperature Superconductors," J. de Physique 49, C6-447 (1988).

Patel, J. R., Berreman, D. W., Sette, F., Citrin, P. H, Rowe, J. E., Cowan, P. L., Jach. T., and Karlin, B., "Substrate Surface Relaxation for C 2 and $\mathrm{S}$ on $\mathrm{Cu}(001)$," Phys. Rev. B 40, 1330 (1989).

Powell, C. J., editor, "Technical Activities 1988 - Surface Science Division, NISTIR 89-4025 (1988).

Powell, C. J., "Cross Sections for Inelastic Electron Scattering in Solids, " Ultramicroscopy 28, 24 (1989).

Ramaker, D. E., Madey, T. E., Kurtz, R. L., and Sambe, H., "SecondaryElectron Effects in Photon-Stimulated Desorption," Phys. Rev. B. 38 , 2099 (1988).

Richter, L. J., Buntin, S. A., Cavanagh, R. R., and King, D. S., "NonBoltzmann Rotational and Inverted Spin-Orbit State Distributions for Laser-Induced Desorption of No from Pt(111)," J. Chem. Phys. 89, 5344 (1988).

Schmidt, W. A., Melmed, A. J., Lovisa, M. F., Naschitzi, M., and Block, J. H., "Field-Ion Energy Spectroscopy of Gold Overlayers on Silicon," Surface Sci. 194, 127 (1988).

Shivaprasad, S. M., Demmin, R. A., and Madey, T. E., "Characterization of Ultrathin Pt Overlayers Deposited on W(110) Surface," Thin Solid Films $\underline{163}, 393$ (1988).

Steigerwald, D. A., Jacob, I., and Egelhoff, Jr., W. F., "Structural Study of the Epitaxial Growth of fcc-Fe Films, Sandwiches, and Superlattices on $\mathrm{Cu}(100)$," Surface Sci. 202, 472 (1988).

Stiles, M. D. and Hamann, D. R., "Ballistic Electron Transmission Through Interfaces," Phys. Rev. B $\underline{38}, 2021$ (1988).

Stiles, M. D. and Hamann, D. R., "Electron Transmission Through $\mathrm{NiSi}_{2}-\mathrm{Si}$ Interfaces," Phys. Rev. B 40, 1349 (1989).

Yarmoff, J. A. and Joyce, S. A., "Bond Selective Chemistry with PhotonStimulated Desorption," Synchrotron Radiation in Materials Research, J. H. Weaver, J. Gland, and R. Clarke, eds., (Materials Research Society Symposium Proceedings, Pittsburgh, 1989) p. 91.

Yarmoff, J. A. and Joyce, S. A., "Photon-Stimulated Desorption as a Measure of Surface Electronic Structure," J. Vac. Sci. Tech. A I, 2445 (1989).

Yarmoff, J. A. and Joyce, S. A., "Photon-Stimulated Desorption of Fluorine from Silicon via Silicon Core Excitations," Phys. Rev. B 40, 3143 (1989). 


\section{B. Publications in Progress}

Balasubramanian, V., Sathyamurthy, N., and Gadzuk, J. W., "Fractals in Molecule-Surface Collisions, Surface Sci. Lett. (in press).

Buntin, S. A., Richter, L. J., King, D. S., Cavanagh, R. R., "StateResolved Evidence for Hot Carrier Driven Surface Reactions: LaserInduced Desorption of NO from Pt(111)," J. Chem. Phys. (in press).

Camus, P. P., "Atom Probe Field-Ion Microscopy Applications," High Temperature Science (in press).

Camus, P. P., Elswijk, H. B., and Melmed, A. J., "Oxygen Concentration of $\mathrm{Eu}_{1} \mathrm{Ba}_{2} \mathrm{Cu}_{3} \mathrm{O}_{7-x}$ in Vacuum. An Atom Probe Study II," J. de Physique (in press).

Camus, P. P., Shull, R. D., and Melmed, A. J., "APFIM Analys is of Composite Magnetic Thin Films," J. de Physique (in press).

Demmin, R. A., Kurtz, R. L., Stockbauer, R., Madey, T. E., Mueller, D. R., and Shih, A., "Photoemission Studies of Pt Overlayers on W(110)," J. Chem. Phys. (submitted).

Drachsel, W., Alvensleben, L. V., and Melmed, A. J., "Time Focusing in a Field Pulsed Atom Probe with a Reflectron," J. de Physique (in press).

Egelhoff, Jr., W. F., "X-Ray Photoelectron and Auger Electron Forward Scattering: A New Tool for Surface Crystallography," Critical Reviews in Solid State and Materials Science (in press).

Elswijk, H. B., Melmed, A. J., and Camus, P. P., "Oxygen Concentration of $\mathrm{Eu}_{1} \mathrm{Ba}_{2} \mathrm{Cu}_{3} \mathrm{O}_{7-x}$ in Vacuum: An Atom Probe Study," J. de Physique (in press).

Elswijk, H. B., Melmed, A. J., and Camus, P. P., "Oxygen Concentration of $\mathrm{EuBa}_{2} \mathrm{Cu}_{3} \mathrm{O}_{7-x}$ in Vacuum: An Atom Probe Study," Appl. Phys. Letters (submitted).

Erickson, N. E. and Powell, C. J., "Energy Transfers in the Quasi-Elastic Scattering of 70-1250 eV Electrons by Surfaces," Phys. Rev. B (in press).

Fowler, H. A., Melmed, A. J., and Elswijk, H. B., "Simulation of Field Ion Microscope Images for the Al-Mn Icosahedral Phase," Phil. Mag. (in press).

Gadzuk, J. W. and Clark, C. W., "Resonance Enhanced Electron Stimulated Desorption," J. Chem. Phys. (in press). 
Gadzuk, J. W., "Electron Scattering from Molecules Adsorbed on Surfaces," in Aspects of Electron-Molecule Scattering and Photoionization, American Institute of Physics Conference Proceedings Series (in press).

Gadzuk, J. W., "Pumping and Probing: Dynamics and Spectroscopy in the Time Domain," Proceedings of Dynamics and Kinetics of Interface Reactions Conference, Springer Series in Surface Science (in press).

Gadzuk, J. W., "Chaos in Surface Dynamics," in Chemistry and Physics of Solid Surfaces, Vol. VIII, Springer Series in Surface Science (in press).

Gadzuk, J. W., "New Theoretical Aspects of DIET," in Desorption Induced by Electronic Transitions (DIET)-IV, Springer Series in Surface Science (in press).

Heinrich, B., Cochran, J. F., Arrott, A. S., Purcell, K. B., and Egelhoff, Jr., W. F., "Development of Magnetic Anisotropies in Ultrathin Epitaxial Films of $\mathrm{Fe}(001)$ and $\mathrm{Ni}(001)$," Physics A (in press).

Jach, T., Hembree, G., and Holdeman, L. B., "Observation of Gold Thin-Film Growth with Reflection Electron Microscopy," Thin Solid Films (submitted).

Jach, T., Novotny, D. B., Bedzyk, M. J., and Shen, Q., "Direct Observation of Surface-Trapped Diffracted Waves," Phys. Rev. B (in press).

Kurtz, R. L., Robey, S. W., and Stockbauer, R. L., "Resonant

Photoemission Studies of High Temperature Superconductors at the NIST SURF-II Synchrotron," Synchrotron Radiation News (submitted).

Kurtz, R. L., Robey, S. W., Stockbauer, R. L., Mueller, D., Shih, A., Toth, L., Singh, A. K., and Osofsky, M., "Electronic Structure of High-T Superconductors Studied Using Photoelectron Spectroscopy," Vacuum (in press).

Kurtz, R. L., Stockbauer, R. L., Madey, T. E., Roman, E., de Segovia, J. L., and Chen, H. H., " $\mathrm{H}_{2} \mathrm{O}$ Chemisorption on $\mathrm{TiO}_{2}$ Surfaces: The Role of Defects," Proceedings of the Symposium on Chemically Modified Oxide Surfaces (in press).

Lince, J. R., Stewart, T. B., Hills, M. M., Fleischchauer, P. D., Yarmoff, J. A., and Taleb-Ibrahimi, A., "Photoelectron Spectroscopic Study of the Interaction of Thin Fe Films with the $\mathrm{MoS}_{2}(0001)$," Surface Sci. (in press).

Lindle, D. W., Cowan, P. L., Jach, T., LaVilla, R. E., Deslattes, R. D., and Perera, R. C. C., "X-Ray Polarized Fluorescence Studies of Small Molecules," Phys. Rev. A (submitted). 
Madey, T. E., Joyce, S. A., and Benndorf, C., "The Role of Alkalis in Desorption Induced by Electronic Transitions," in Alkali Adsorption on Metals and Semiconductors (in press).

Madey, T. E., Joyce, S. A., and Johnson, A. L., "The Structure of Molecules on Surfaces as Determined using Electron Stimulated Desorption," Proceedings of Spring College on Condensed Matter Physics (in press).

Marton, D. and Fine, J., "Sputtering-Induced Surface Roughness of Metallic Thin Films," Thin Solid Films (in press).

Marton, D. and Fine, J., "Ion Bombardment Induced Diffusion: A Case Study on a Sputtered Ag/Ni Layered System," Periodica Polytechnicia Chemical Engineering (in press).

Marton, D. and Fine, J., "Ion-Induced Radiation-Enhanced Diffusion of Silver in Nickel," Mat. Sci. Eng. (in press).

Melmed, A. J., Elswijk, H. B., and Fowler, H. A., "Field Ion Microscope Image Simulations for Icosahedral Al-Mn," J. de Phys. (in press).

Mintz, M. H., Shuker, P., and Fine, J., "Direct Detection of Atom Vaporization by Laser Resonance Ionization as a Probe of Gas-Surface Chemisorption Mechanisms," Phys. Rev. Letters (submitted).

Nenadovic, T., Popovic, N., and Fine, I., "Mechanical Sputtering of Structural Stainless Steels," J. Mat. Sci. (in press).

Perera, R. C. C., Cowan, P. L. Lindle, D. W., LaVilla, R. E., Jach, T., and Deslattes, R. D., "Molecular-Orbital Studies via Satellite-Free X-Ray Fluorescence: $C l$ K-Absorption and K-V Emission Spectra of Chlorofluoromethanes," Phys. Rev. A. (submitted).

Powell, C. J., "The Surface Sensitivity of Electron Spectroscopies," Current Contents, Physical, Chemical, and Earth Sciences (submitted).

Powell, C. J., "Progress and Pitfalls in Quantitative Surface Analysis by Auger-Electron Spectroscopy and X-Ray Photoelectron Spectroscopy, " in New Developments and Trends in Surface Science (submitted).

Powell, C. J. and Seah, M. P., "Precision, Accuracy, and Uncertainty in Quantitative Surface Analyses by Auger-Electron Spectroscopy and X-Ray Photoelectron Spectroscopy," J. Vac. Sci. Tech. A (submitted).

Schwarzacher, W., Allison, W., Willis, R. F., Penfold, J., Ward, R. C., and Egelhoff, Jr., W. F., "Variation in Magnetic Properties of Cu/fcc $\mathrm{Fe} / \mathrm{Cu}(001)$ Sandwich Structures," Solid State Commun. (in press).

Shapiro, M. H. and Fine, J., "Molecular Dynamics Simulation of Collisional Excitation in Sputtering From Al," Nucl. Instr. \& Meth. B (in press). 
Steigerwald, D. A. and Egelhoff, Jr., W. F., "Two Simple, Metal Vapor Deposition Sources for a Downward Evaporation in Ultra-High Vacuum," J. Vac. Sci. Tech. (in press).

Stiles, M. D. and Hamann, D. R., "Electron Transmission Through Silicon Stacking Faults," Phys. Rev. B (submitted).

Stockbauer, R. L., Robey, S. W., Kurtz, R. L., Mueller, D., Shih, A., Singh, A. K., Toth, L., and Osofsky, M., "Resonant Photoemission and Chemisorption Studies of $\mathrm{Tl}-\mathrm{Ba}-\mathrm{Ca}-\mathrm{Cu}-\mathrm{O}$," in Proceedings of American Vacuum Society Topical Conference on High $T_{c}$ Superconducting Thin Films, Devices, and Characterization (in press).

Tanuma, S., Powell, C. J., and Penn, D. R., "Material Dependence of Electron Inelastic Mean Free Paths at Low Energies," J. Vac. Sci. Tech. A (submitted).

Tanuma, S., Powel1, C. J., and Penn, D. R., "Electron Inelastic Mean Free Paths in Solids at Low Energies," J. Elect. Spect. (in press).

Thurgate, S. M. and Erickson, N. E., "XPS/Ar' Ion Profile Study of Thin Oxide Layers on InP," J. Vac. Sci. Tech. A (submitted).

Whitman, L. J., Joyce, S. A., Yarmoff, J. A., McFeely, F. R., and Terminello, L. J., "Summary Abstract: The Chemisorption of $\mathrm{SiCl}_{4}$, $\mathrm{Si}_{2} \mathrm{Cl}_{6}$, and Chlorine on $\mathrm{Si}(111) 7 \times 7, "$ Vacuum (submitted). 
C. Recent Publications of New Staff Members Resulting From Previous Positions

(Beckerle and Whitman)

Beckerle, J. D., Johnson, A. D., and Ceyer, S. T., "Collision Induced Dissociation and Desorption: $\mathrm{CH}_{4}$ on $\mathrm{Ni}(111)$," Springer Series in Surface Sciences Vol. 14, Solvay Conference on Surface Science, $F$. W. de Wette, ed., (Springer-Verlag, Berlin, 1988), p. 109.

Beckerle, J. D., Johnson, A. D., Yang, Q. Y., and Ceyer, S. T., "Summary Abstract: Collision Induced Dissociation and Desorption: $\mathrm{CH}_{4}$ and $\mathrm{CO}$ on $\mathrm{Ni}(111), " \mathrm{~J} . \mathrm{Vac}$. Sci. Tech. A 6 , 903 (1988).

Beckerle, J. D., Yang, Q. Y., Johnson, A. D., and Ceyer, S. T., "Adsorption of $\mathrm{CO}$ and $\mathrm{O}_{2}$ on $\mathrm{Ni}(111)$ at $8 \mathrm{~K}, "$ Surface Sci. 195, 77 (1988).

Beckerle, J. D., Johnson, A. D., and Ceyer, S. T., "Collision-Induced Dissociation Chemisorption of $\mathrm{CH}_{4}(\mathrm{ad}) / \mathrm{Ni}(111)$ : The Mechanism for Chemistry with a Hammer," J. Chem. Phys. (in press).

Mieher, W. D., Whitman, L. J., and Ho, W., "A Time Resolved Electron Energy Loss Spectroscopy Study of CO on Pt(111): Adsorption Site Occupations Versus Coverage and Temperature," J. Chem. Phys. 91, 3228 (1989).

Richter, L. J., Mieher, W. D., Whitman, L. J., Noonan, W. A., and Ho, W., "Improved Multidetector for Time-Resolved Electron Energy Loss Spectroscopy,." Rev. Sci. Instrum. 60, 12 (1989).

Whitman, L. J. and Ho, W., "Dissociation Kinetics on an Alkali MetalPromoted Surface: NO and K on Rh(100)," Surface Sci. 204, L725 (1988).

Whitman, L. J. and Ho, W., "The Kinetics and Mechanisms of Alkali MetalPromoted Dissociation: Adsorption and Reaction of NO on PotassiumPrecovered Rh(100)," J. Chem. Phys. $\underline{89}, 7621$ (1988).

Whitman, L. J. and Ho, W., "Desorption Kinetics on an Alkali MetalPrecovered Surface: CO and K on Pt(111)," J. Chem. Phys. 90, 6018 (1989).

Whitman, L. J., Richter, L. J., Gurney, B. A., Villarrubia, J. S., and Ho, W., "CO Adsorption Site Occupations on $\mathrm{Fe}(111)$ vs. Coverage and Temperature: The Kinetics of Adsorption and Reaction," J. Chem. Phys. 90, 2050 (1989). 


\section{PATENT ACTIONS}

Patent Application: "Diffraction Device Which Detects the Bragg Condition," T. Jach and J. C. Geist, G. P. Carver, and D. B. Novotny of the NIST Semiconductor Electronics Division, U.S. Ser. No. 17/232.243.

Patent Disclosure: "Amorphous Silicon X-Ray Normalizing Detector," T. Jach and J. C. Geist of the NIST Semiconductor Electronics Division.

Patent Disclosure: "Scanning Scattering Microscope," J. Fine and D. Marton. 


\section{TALKS}

Beckerle, J., "Time Dependent Studies of Vibrational Relaxation Dynamics of CO ( $v=1)$ on Metal Surfaces," Topical Meeting on Microphysics of

Surfaces, Beams, and Adsorbates, Salt Lake City, UT, February, 1989.

Beckerle, J., "Time-Resolved Studies of Vibrational Relaxation of CO ( $v=1$ ) on Metal Particle Surfaces," International Conference on Time-Resolved Vibrational Spectroscopy, Princeton, NJ, June 14, 1989.

Beckerle, J., "Time-Resolved Studies of Vibrational Relaxation of CO (V=1) on Metal Particle Surfaces," Gordon Research Conference, Andover, NH, August 9, 1989.

Buntin, S., "Photogenerated 'Hot' Electron Induced Desorption of NO from Pt(111)," Chemistry Department, Argonne National Laboratory, Argonne, IL, January 23, 1989.

Buntin, S., "Photogenerated 'Hot' Electron Induced Desorption of No from Pt(111)," Department of Chemical Physics Seminar, Aerodyne Corporation, Department of Chemical Physics, Billrica, MA, March 23, 1989.

Buntin, S., "Dynamics in Laser-Induced Desorption of NO from Pt(111)," Chemical Physics Group, Los Alamos National Laboratory, Los Alamos, NM, May 8, 1989.

Buntin, S., "Dynamics in Laser-Induced Desorption of No from Pt(111), "New Mexico Chapter of the American Vacuum Society, Albuquerque, NM, May 11 , 1989.

Buntin, S., "Quantum-State-Specific Dynamics in the Laser-Induced Desorption of NO from Pt(111)," 1989 Conference on the Dynamics of Molecular Collisions, Asilomar Conference Center, Asilomar, CA, July $20,1989$.

Camus, P., "Ultra-High Spatial Resolution Composition Analysis Application of Atom Probe Field Ion Microscopy to Alloy Clustering and Segregation," Sixth International Conference on High Temperatures, National Institute of Standards and Technology, Gaithersburg, MD, April 3,1989 .

Camus, P., "APFIM Analysis of Composite Magnetic Thin Films," International Field Emission Symposium, Oxford, England, July 31, 1989.

Cavanagh, R. R., "Laser Probes of Surface Dynamics: Distinguishing Photochemistry From Thermal Chemistry," Department of Chemistry, University of Pittsburgh, Pittsburgh, PA, October 27, 1988.

Cavanagh, R. R., "Time Resolved Measurements of Vibrational Relaxation at Surfaces: Phonons vs. Electron-Hole Pairs," Department of Chemistry, University of Illinois, Chicago, IL, November 3, 1988. 
Cavanagh, R. R., "Laser Probes of Surface Dynamics: Distinguishing Photochemistry From Thermal Chemistry," Department of Chemistry, Northwestern University, Chicago, IL, November 4, 1988.

Cavanagh, R. R., "Laser-Induced Desorption: State-Resolved Evidence for Optically Driven Surface Reactions," Molecular \& Surface Dynamics Seminar, University of Pennsylvania, Philadelphia, PA, March 31, 1989.

Cavanagh, R. R., "Laser Induced Desorption of No from Pt(111): The Role of Hot Carriers," Surface Physics Group, AT\&T Bell Laboratories, Murray Hill, NJ, May 5, 1989.

Cavanagh, R. R., "Laser Probes of Transient Excited States at Surfaces," Gordon Research Conference, Andover, NH, August 9, 1989.

Cavanagh, R. R., "Laser Induced Desorption of NO from Pt(111): Evidence for Hot Carrier Driven Reactions," American Chemical Society Meeting, Miami, FL, September 14, 1989.

Egelhoff, Jr., W. F., "Epitaxy of Ag, $\mathrm{Cu}, \mathrm{Fe}$, and $\mathrm{Mn}$ on $\mathrm{Ag}(100)$ and $\mathrm{Cu}(100)$ : RHEED Oscillations at $77 \mathrm{~K}$," American Vacuum Society Meeting, Atlanta, GA, October 5, 1988.

Egelhoff, Jr., W. F., "Spin-Polarized-Neutron Reflection Measurements on Epitaxial fcc-Fe/Cu(100) Films," American Physical Society Meeting, st. Louis, MO, March 20, 1989.

Egelhoff, Jr., W. F., "The Growth of High-Quality Epitaxial Sandwich Structures on $\mathrm{Mn}$ and $\mathrm{Fe}$ on $\mathrm{Ag}(100)$, "American Physical Society Meeting, St. Louis, MO, March 21, 1989.

Egelhoff, Jr., W. F., "The Role of Adsorbed Gases in Metal on Metal Epitaxy," American Physical Society Meeting, st. Louis, MO, March 21, 1989.

Egelhoff, Jr., W. F., "RHEED Oscillations at 77K in Metal on Metal Epitaxy," American Physical Society, St. Louis, MO, March 24, 1989.

Egelhoff, Jr., W. F., "XPS and Auger Forward Scattering: A Structural Tool for Studying Ultrathin Films, Epitaxial Growth, Surface Segregation, and Interdiffusion," Materials Science and Technology Division, Naval Research Laboratories, Washington, D.C., May 10, 1989.

Egelhoff, Jr., W. F., "XPS Forward Scattering Studies of Epitaxial Films," Surface Canada Conference, Vancouver, B.C., Canada, May 31, 1989.

Egelhoff, Jr., W. F., "XPS Forward Scattering Studies of Epitaxial Growth Modes of Magnetic Thin Films," Office of Naval Research Workshop on Monolayer Magnetism, Berkeley Springs, WV, August 16, 1989. 
Fine, J., "Interface Modification During Sputter Depth Profile Analysis," American Vacuum Society National Symposium, Atlanta, GA, October 4, 1988.

Fine, J., "Nanometer Depth Analysis of Sputter Profiles Interfaces," Eleventh International Vacuum Congress and Seventh International Conference on Solid Surfaces," Cologne, W. Germany, September 29, 1989.

Gadzuk, J. W., "Semiclassical Dynamics of Molecules at Electronically Excited Surfaces," Solid State Physics Colloquium, Cornell University, Ithaca, NY, November 8, 1988.

Gadzuk, J. W., "Real-Time Dynamics of Molecular Processes at Surfaces by Femtosecond Excitation," NIST Staff Research Seminar, National Institute of Standards and Technology, Gaithersburg, MD, February 17 , 1989 .

Gadzuk, J. W., "Shape Resonance-Enhanced Electron Stimulated Desorption," American Physical Society, St. Louis, MO, March 21, 1989.

Gadzuk, J. W., "Real-Time Dynamics of Molecular Processes at Surfaces by Femtosecond Excitation," Workshop on Dynamics of Surface Reactions, Copenhagen, Denmark, May 9, 1989.

Gadzuk, J. W., "Vibrational Relaxation in Molecules Adsorbed on Metal Clusters," Surface Science Center Colloquium, University of Liverpool, Liverpool, England, May 15, 1989.

Gadzuk, J. W., "Aspects of Surface Physics Theories," Washington Academy of Science Awards Banquet, Washington, DC, May 18, 1989.

Gadzuk, J. W., "Electron Scattering off Molecules Adsorbed on Surfaces," Aspects of Electron-Molecule Scattering and Photoionization Conference, Yale University, New Haven, CT, July 23, 1989.

Gadzuk, J. W., "Pumping and Probing: Dynamics and Spectroscopy in the Time Domain," Fourth Annual Joint Workshop on Interface Phenomena, Campobello Island, ME, August 17, 1989.

Gadzuk, J. W., Chaos in Surface Dynamics," International Summer Institute in Surface Science, University of Wisconsin-Milwaukee, Milwaukee, WI, August 24, 1989.

Gadzuk, J. W., "Excitement in Electron Scattering from Adsorbed Molecules," National Institute of Standards and Technology Neutron Physics Seminar, September $28,1989$.

Jach, T., "X-ray Standing Waves, Grazing Angles, and Atomic Positions," Department of Physics, Purdue University, Lafayette, IN, November 3, 1988. 
Jach, T., "X-ray Standing Waves, Grazing Angles, and Atomic Positions," Department of Physics and Chemistry, Indiana University, Bloomington, IN, November 4, 1988.

Jach, T., "The Berry Phase," Laser Physics Group, National Institute of Standards and Technology, Gaithersburg, MD, January 11, 1989.

Jach, T., "X-ray Diffraction, Glancing Angles, and Atomic Positions," Physics Department Colloquium, University of Virginia, Charlottesville, VA, February 17, 1989.

Jach, T., "Direct Observation of the Superficial Wave Predicted by the Dynamical Theory of X-Ray Diffraction at Glancing Angle," 9 th General Conference of the Condensed Matter Division of the European Physical Society, Nice, France, March 8, 1989.

Jach, T., "Direct Observation of the Superficial Wave Predicted by the Dynamical Theory of X-Ray Diffraction at Glancing Angle," Gordon Research Conference on X-Ray Physics, New London, NH, August 9, 1989.

Jach, T., "X-ray Diffraction, Standing Waves, and Atomic Positions," Department of Physics, University of Dortmund, Dortmund, W. Germany, September 13, 1989.

Jach, T., "X-ray Diffraction, Standing Waves, and Atomic Positions," Hamburg Synchrotron Radiation Laboratory, Hamburg, W. Germany, September 15, 1989 .

Jach, T., "Determining Atomic Positions by X-ray Standing Waves in New Geometries," Ris $\varnothing$ National Laboratory, Roskilde, Denmark, September 18 , 1989.

Jach, T., "X-ray Standing Waves in New Geometries to Measure Atomic Positions," Department of Physics, Chalmers University, Goteborg, Sweden, September 20, 1989.

Jach, T., "Grazing Angle X-Ray Standing Wave Measurements of Iodine and Chlorine on the (111) Surface of Germanium," Joint 11 th International Vacuum Congress and the 7 th International Conference on Solid Surfaces, Cologne, W. Germany, September 25, 1989.

Joyce, S. A., "The Chemisorption of HF on Silicon," Material Research Society Conference, Boston, MA, December 1, 1988.

Joyce, S. A., "The Effect of Potassium on the Chemisorption of $\mathrm{PF}_{3}$ on $\mathrm{Ru}(0001)$ as Studied by Positive and Negative Ion Electron Stimulated Desorption Ion Angular Distributions (ESDIAD)," American Physical Society Meeting, St. Louis, MO, March 22, 1989. 
Joyce, S. A., "Determination of the Geometric and Electronic Structure of Adsorbates Using Stimulated Desorption Techniques," Chemistry and Physics Laboratory, Aerospace Corporation, Los Angeles, CA, April 12, 1989.

Joyce, S. A., "Determination of Adsorbate Structures Using Stimulated Desorption Techniques," Surface Science Department, Sandia National Laboratories, Albuquerque, NM, April 27, 1989.

Joyce, S. A., "Determination of Adsorbate Structures Using Stimulated Desorption Techniques," Surface Science Division, Hoechst-Celanese, Inc., Summit, NJ, May 23, 1989.

Joyce, S. A., "Determination of Adsorbate Structures Using Stimulated Desorption Techniques," Argonne National Laboratories, Argonne, IL, June 1, 1989.

Joyce, S. A., "Influence of Alkali Metal Coadsorption on the Charge State of Desorbed Ions," Gordon Research Conference, Andover, NH, August 8 , 1989 .

Kurtz, R. L., "Decomposition of Hydrogenic Species on $\mathrm{TiO}_{2}$ Studied with Resonant Photoemission," American Physical Society Meeting, St. Louis, MO, March 21, 1989.

Kurtz, R. L., "Resonant Oxygen Satellites in Photoemission from High- $\mathrm{T}_{c}$ Superconductors," American Physical Society Meeting, St. Louis, MO, March 22, 1989.

Kurtz, R. L., "Water Adsorption on $\mathrm{TiO}_{2}$ Surfaces," Chemically Modified Oxide Surfaces Symposium, Midland, MI, May 29, 1989.

Melmed, A. J., "FIM of High-Tc Materials," American Vacuum Society National Symposium, Atlanta, GA, October 3, 1988.

Melmed, A. J., "Field Ion Microscopy of High Transition Temperature Superconductors," Naval Surface Weapons Laboratory, Silver Spring, MD, November $16,1988$.

Melmed, A. J., "Oxygen Concentration in the Near-Surface Region of $\mathrm{EuBa}_{2} \mathrm{Cu}_{3} \mathrm{O}_{7-x}$ in Vacuum," Fifth NIST Superconductivity Information Exchange Meeting, Boulder, CO, September 20, 1989.

Powell, C. J., "Precision, Accuracy, and Uncertainty in Quantitative Surface Analyses by AES and XPS," American Vacuum Society Meeting, Atlanta, GA, October 4, 1988 .

Powell, C. J., "High-Accuracy Measurements of XPS Binding Energies and AES Kinetic Energies for Copper, Silver, and Gold," American Vacuum Society Meeting, Atlanta, GA, October 5, 1988. 
Powell, C. J., "Precision, Accuracy, and Uncertainty in Quantitative Surface Analyses by AES and XPS," Fifth International Conference on Quantitative Surface Analysis, London, England, November 15, 1988.

Powell, C. J., "Electron Inelastic Mean Free Paths and Attenuation Lengths for Auger-Electron Spectroscopy and X-Ray Photoelectron Spectroscopy," 5 th International Conference on Quantitative Surface Analysis, London, UK, November 16, 1988.

Powel1, C. J., "High-Accuracy Measurements on XPS Binding Energies and AES Kinetic Energies for Copper, Silver, and Gold," Fifth International Conference on Quantitative Surface Analysis," London, England, November 17,1988 .

Powel1, C. J., "International Efforts to Develop Reference Procedures, Reference Data, and Reference Materials for Surface Chemical Analysis," Pittsburgh Conference, Atlanta, GA, March 8, 1989.

Powel1, C. J., "Electron Inelastic Mean Free Paths and Attenuation Lengths for Quantitative Surface Analyses by AES and XPS," University of Kaiserslautern, Kaiserslautern, W. Germany, May 19, 1989.

Powell, C. J., "Reference Materials for the Quantification of Surface Analyses," European Central Bureau of Nuclear Measurements, Geel, Belgium, May 25, 1989.

Powell, C. J., "Standard Reference Materials for Surface Analysis," Workshop on Standard Reference Data and Reference Materials for Surface Analysis, Cleveland, OH, May 30, 1989.

Powell, C. J., "Progress and Pitfalls in Quantitative Surface Analysis by AES and XPS," Eleventh Symposium on Applied Surface Analys is, Cleveland, $\mathrm{OH}$, June 2, 1989.

Powe 11, C. J., "Electron Inelastic Mean Free Paths in Solids at Low Energies," Fourth International Conference on Electron Spectroscopy, University of Hawaii, Honolulu, HI, July 13, 1989.

Powel1, C. J., "Electron Inelastic Mean Free Paths in Solids at Low Energies," Eleventh International Vacuum Congress and Seventh International Conference on Solid Surfaces, Cologne, W. Germany, September $26,1989$.

Richter, L. J., "Wavelength Dependent Dynamics in Laser Driven Surface Reactions: Photogenerated Electron Induced Desorption of NO from Pt(111)," American Vacuum Society Meeting, Atlanta, GA, October 4, 1988 .

Richter, L. J., "Quantum-State Specific Studies of the Dynamics of Excitation and Desorption of NO from Pt(111)," Laboratory of Surface Modification Interface Dynamics Group, Rutgers University, Piscataway, NJ, February 9, 1989. 
Richter, I. J., "Quantum-State Specific Studies of the Dynamics of Excitation and Desorption from Surfaces," Department of Physics, Brown University, Providence, RI, February 22, 1989.

Richter, L. J., "Quantum-State Specific Measurements of the Laser-Induced Desorption of NO from Si(111)," Physical Electronics Conference, University of Seattle, Seattle, WA, June 27, 1989.

Richter, L. J., "State Specific Studies of the Laser-Induced Desorption of NO from Si(111)," Gordon Research Conference, Andover, NH, August 9, 1989 .

Robey, S. W., "Photoemission Investigation of Reactive Ion Etched Ge and SiGe Alloy Surfaces," American Physical Society Meeting, St. Louis, MO, March 21, 1989.

Robey, S. W, "Synchrotron Radiation Studies of High Temperature Superconductors," Fifth NIST Superconductivity Information Exchange Meeting, Boulder, CO, September 20, 1989.

Stiles, M. D., "Theory of Electrical Transmission Through Epitaxial Interfaces," American Physical Society Meeting, St. Louis, MO, March $20,1989$.

Stiles, M. D., "Electron Transmission Through Interfaces," IBM Research Center, Yorktown Heights, NY, April 15, 1989.

Stiles, M. D., "Distorted-Wave-Born-Approximation Calculations of Inelastic Scattering," Workshop on Dynamics of Surface Reactions, Copenhagen, Denmark, May 9, 1989.

Stiles, M. D., "Electron Transmission Through Interfaces, "University of Virginia, Department of Physics, Charlottesville, VA, September 21, 1989 .

Stockbauer, R. L., "Resonant Photoemission and Chemisorption Studies of Ti-Ba-Ca-Cu-O," American Vacuum Society Meeting, Atlanta, GA, October 3,1988 .

Stockbauer, R. L., "Studies of Electronic Interactions and Material Degradation of High Temperature Superconductors, "Workshop on the Materials Science of $\mathrm{High} \mathrm{T}_{\mathrm{c}}$ Superconductors: Magnetic Interactions, National Institute of Standards and Technology, Gaithersburg, MD, October $20,1988$.

Stockbauer, R. L., "Photoemission Studies of $\mathrm{T} \ell$ based High $T_{c}$ Superconductors," Fourth NIST Superconductivity Information Exchange Meeting, National Institute of Standards and Technology, Gaithersburg, MD, December 13, 1988. 
Stockbauer, R. L., "Photoemission Studies of the Initial Stages of Decomposition of High $\mathrm{T}_{c}$ Superconductors," American Physical Society Meeting, St. Louis, MO, March 21, 1989.

Stockbauer, R. L., "The Surface Chemistry of High-Temperature Superconductors," Scanning Microscopy Meeting, Salt Lake City, UT, May 3,1989 .

Whitman, L., "Desorption Kinetics on an Alkali Metal-Precovered Surface: Co and $K$ on Pt(111)," Physical Electronics Conference, University of Seattle, Seattle, WA, June 26, 1989.

Whitman, L., "Chemisorption of Chlorosilanes on Silicon," Gordon Research Conference, Andover, NH, August 8, 1989.

Yarmoff, J. A., "Synchrotron Radiation Studies of the Silicon-Fluorine Interaction," IBM Almaden Research Center, Almaden, CA, October 24, 1988.

Yarmoff, J. A., "Synchrotron Radiation Studies of the Silicon-Fluorine Interaction," Advanced Light Source Department, Lawrence Berkeley Laboratory, Berkeley, CA, October 25, 1988.

Yarmoff, J. A., "Synchrotron Radiation Studies of the Silicon-Fluorine Interaction," Department of Physics, University of California, Riverside, CA, October 27, 1988.

Yarmoff, J. A., "Bond Selective Chemistry with Photon Stimulated Desorption," Materials Research Society Conference, Boston, MA, December 1, 1988 .

Yarmoff, J. A., "Synchrotron Radiation Studies of Silicon-Fluorine Interactions," Physical Chemistry Research Department, AT\&T Bell Laboratories, Murray Hill, NJ, April 5, 1989.

Yarmoff, J. A., "Studies of Semiconductor Surfaces," University of California, Riverside, CA, June 14, 1989.

Yarmoff, J.A., "Photoemission Cross-Sections and Electron Attenuation Lengths at $\mathrm{SiO}_{2} / \mathrm{Si}$ Interfaces," Fourth International Conference on Electron Spectroscopy, University of Hawaii at Manoa, Honolulu, HI, July 13, 1989.

Yarmoff, J. A., "Bond-Selective Photon Stimulated Desorption, Ninth International Conference on Vacuum Ultraviolet Physics, University of Hawaii at Manoa, Honolulu, HI, July 19, 1989.

Yarmoff, J. A., "Bond-Selective Photon Stimulated Desorption," Synchrotron Radiation Instrumentation Conference, University of CaliforniaBerkeley, Berkeley, CA, August 7, 1989. 
Yarmoff, J. A., "Chemisorption of Chlorosilanes on Silicon," Eleventh International Vacuum Conference and Seventh International Conference on Solid Surfaces, Cologne, W. Germany, September 26, 1989. 
Alkemade, P. F. A., "Production of Auger Electrons by Ions under Channeling and Random Conditions," Interface Science Western, Department of Physics, The University of Western Ontario, London, Ontario, Canada, January, 9, 1989 .

Batson, P. E., "Spatially Resolved Electron Energy Loss Spectroscopy: Bonding and Electronic Structure from Sub-Nanometer Sized Areas," IBM Thomas J. Watson Research Center, Yorktown Heights, NY, Interface Science Seminar Series, April 7, 1989.

Bedzyk, M., "Long-Period X-ray Standing Waves," Cornell High Energy Synchrotron Source, Cornell University, Ithaca, NY, Interface Science Seminar Series, February 1, 1989.

Barojas-Blaisten, E., "Molecular Dynamics Simulation of Clusters Adsorbed on a Surface," Surface Science Division Seminar, National Institute of Standards and Technology, Gaithersburg, MD, January 4, 1989.

Brillson, L. J., "New Techniques for Characterizing and Controlling MetalSemiconductor Interfaces," Xerox Webster Research Center, Webster, NY, Interface Science Seminar Series, June 14, 1989.

Bristowe, P. D., "Diffraction from Grain Boundaries in Gold: Recent Observations and Computer Simulations," Massachusetts Institute of Technology, Cambridge, MA, Interface Science Seminar Series, November 16,1988 .

Cheng, Y.-T., "Fractal Geometric and Thermodynamic Aspects of Ion-Solid Interactions," Physical Chemistry Department, General Motors Research Laboratories, Warren, MI, Interface Science Seminar Series, March 17, 1989.

Dieleman, J., "Low Energy Ion and Laser Assisted Surface Reactions," Philips Research Laboratories, Eindhoven, The Netherlands, December 5 , 1988.

Elswijk, H., "Atom Probe Field Ion Microscopy of $\mathrm{EuBaCu}_{3} \mathrm{O}_{7-x}$ : Oxygen Depletion in Vacuum," Surface Science Division Seminar, National Institute of Standards and Technology, Gaithersburg, MD, February 28 , 1989.

Fontaine, A., "Time Resolved X-ray Absorption Spectroscopy: Applications to High $\mathrm{T}_{c}$ Superconductivity and Phase Transitions at High Pressure," LURE, Orsay, France, December 6, 1988.

Fuggle, J. C., "Atomic Effects and Strong Magnetic Dichroism in X-ray Absorption of Solids and Surfaces," Laboratorium voor Fysische Chemie, Katholieke Universiteit, Nijmegen, Nederland, April 10, 1989. 
Gadzuk, J. W., "Semiclassical Dynamics of Molecules at Electronically Excited Surfaces," Surface Science Division Seminar, National Institute of Standards and Technology, Gaithersburg, MD, November 21, 1988.

Gray, H. F., "Vacuum Microelectronics: Field Emission Based," Naval Research Laboratory, Washington, DC, March 29, 1989.

Gumhalter, G., Institute of Physics of the University of Zagreb, Zagreb, Yugoslavia, "Dynamic Electronic Structure of Chemisorbed $\mathrm{CO}: 2 \pi^{\text {* }}$ Resonance Features," June 27, 1989.

Gutowski, V., "Physico-Chemical Criteria for Maximum Adhesion," CSIRO, Australia, Interface Science Seminar Series, October 7, 1988.

Harris, J., "Sticking in the Quantum Regime: $\mathrm{H}_{2}$ on $\mathrm{Cu}(110)$," Institut fur Festkorperforschung, KFA, Julich, W. Germany, October 17, 1988.

Holloway, S., "Dynamics of Gas-Surface Scattering: Quantum vs. Semiclassical vs. Classical: When and How?," Liverpool University, Surface Science Research Center, Liverpool, UK, March 7, 1989.

Ishida, H., "Quantitative Surface FT-IR Spectroscopy," Case Western Reserve University, Cleveland, OH, Interface Science Seminar Series, March 1 , 1989.

Jones, R. O., "Density Functional Calculations with Simulated Annealing The Answer to Problems in Condensed Matter and Molecular Physics?," Institut fur Festkorperforschung, der KFA, Julich, West Germany, April 3,1989 .

Kaiser, W. J., "Ballistic-Electron-Emission Microscopy Investigation of Semiconductor Interfaces," California Institute of Technology, Pasadena, CA, Interface Science Seminar Series, May 25, 1989.

Kruse, N., "Kinetics of Surface Reactions on the Atomic Scale," Technical Hochshule, Zurich, Switzerland, October 11, 1988.

Lince, J., "Reactivity, Modification, and Electronic Structure of $\mathrm{MoS}_{2}(0001)$ Surfaces," Aerospace Corporation, El Segundo, CA, August 4, 1989 .

Mancini, D., "X-Ray Lithography and Chemistry of Diazonapthoquinone-novolak Resist," University of Wisconsin-Madison, Madison, WI, March 17, 1989.

Osgood, R. M., "Photon Processing of Materials: Techniques and Basic Surface Physics," Columbia University, New York, NY, Interface Science Seminar Series, January 18, 1989.

Polak, M., "Segregation to Different Surfaces in Polycrystalline Ni-98Al Solid Solution," Department of Materials Engineering, Ben Gurion University of the Negev, Negev, Israel, August 2, 1989. 
Reutt-Robey, J. E., "Microscopic CO Diffusion on a Pt(111) Surface by Time Resolved Surface Infrared Spectroscopy," Department of Chemistry, University of Maryland, College Park, MD, January 11, 1989.

Sathyamurthy, N., "Time-Dependent Quantum Mechanical Approach to Reactive Scattering," Indian Institute of Technology, Kanpur, India, October 12, 1988 .

Schwarzacher, W., "Spin Polarized Neutron Reflection Measurements on Epitaxial fcc $\mathrm{Fe} / \mathrm{Cu}(100)$ Sandwich Structures," Cambridge University, Cavendish Laboratories, Cambridge, England, March 16, 1989.

Semancik, S., "The Chemical and Electronic Character of Sensing Interfaces," NIST Chemical Process Metrology Division, Interface Science Seminar Series, June 8, 1989.

Vernon, M., "Molecular Beam Studies of Organometallic Photodissociation Dynamics," Columbia University, New York, NY, October 19, 1988.

Vvedensky, D. D., "Computer Stimulations of RHEED Oscillations and the Epitaxial Growth of Semiconductors," Imperial College, London, England, November 28,1988 .

Weaver, J. H., "Surfaces and Interfaces of High $T_{c}$ Superconductors," Department of Chemical Engineering and Material Sciences, University of Minnesota, Minneapolis, MN, Interface Science Series, February 16, 1989.

White, R. C., "Electronic Structure and Disordered Systems - What Photoemission Can Tell Us About Metal - Polymer Interfaces," Department of Electrical Engineering and Microelectronics Sciences Laboratories, Columbia University, New York, NY, September 1, 1989.

Zare, R. N., "The $\mathrm{H}+\mathrm{D}_{2}$ Reaction," Stanford University, Chemistry Department, Stanford, CA, November 30, 1988. 


\section{CONFERENCES ORGANIZED}

Applied Surface Science Sessions of the 11 th International Vacuum Congress/7th International Conference on Solid Surfaces, Cologne, Federal Republic of Germany, September 25-29, 1989 (sponsored and organized by the International Union for Vacuum Science, Technique and Applications and the German Vacuum Society).

Third Topical Conference on Quantitative Surface Analysis, Salem, Massachusetts, October 20-21, 1989 (cosponsored by the Applied Surface Science Division of the American Vacuum Society, the New England Combined Chapter of the American Vacuum Society, Committee E-42 on Surface Analysis of the American Society for Testing and Materials (ASTM), and the Surface Chemical Analysis Technical Working Party of the Versailles Project on Advanced Materials and Standards (VAMAS). 


\section{TECHNICAL AND PROFESSIONAL COMMITTEE}

PARTICIPATION AND LEADERSHIP

Cavanagh, R. R.

Treasurer, General Committee of the Physical Electronics Conference

Local Co-Chairman, Physical Electronics Conference, Gaithersburg, MD, June, 1990

National Measurement Laboratory Representative, NIST-NRC Postdoctoral Committee

Member, Organizing Committee, 6 th International Conference on Vibrations at Surfaces, Shelter Island, NY, September, 1990

Member, Executive Committee, Surface Science Division, American Vacuum Society

Member, Surface Science Division Program Committee, American Vacuum Society National Symposium, Boston, MA, October, 1989

Division Laser Safety Officer

Member, NIST Research Advisory Committee

Fine, $J$.

Chairman, Subcommittee E-42.09 on Standard Reference Materials of ASTM Committee E-42 on Surface Analysis

Gadzuk, J. W.

Member, Editorial Advisory Board, "Progress in Surface Science"

Member, International Advisory Committee, 6 th International Conference on Vibrations at Surfaces, Shelter Island, NY, September, 1990

Board Member, Greater Washington Solid State Physics Colloquium

Jach, J .

Division Safety Officer (from 5/89)

Powell, C. J.

Member, Executive Committee, and International Liaison, ASTM Committee E-42 on Surface Analysis

Vice-Chairman, Surface Chemical Analysis Technical Working Party, Versailles Project on Advanced Materials and Standards

Member, Board of Directors, American Vacuum Society

Member, Long Range Planning Committee, American Vacuum Society 
Chairman, Applied Surface Science Division Steering Committee, International Union of Vacuum Science, Technique, and Applications

Chairman, Applied Surface Science Program Committee, 11th International Vacuum Congress and 7 th International Conference on Solid Surfaces, Cologne, Federal Republic of Germany, September 25-29, 1989

Co-Opted Member, Subcommittee on Surface Analysis, Commission V.2 on Microchemical Techniques and Trace Analysis, International Union of Pure and Applied Chemistry

Chairman, Organizing Committee, 3rd Topical Conference on Quantitative Surface Analysis, Salem, MA, October 20-21, 1989

Member, Scientific Committee, European Conference on Applications of Surface and Interface Analysis, Antibes, France, October 23-27, 1989

Member, Editorial Board, "Applications of Surface Science"

Member, Editorial Board, "Surface and Interface Analysis"

Member, Editorial Board, "Methods of Surface Characterization"; coeditor of two volumes in series

Stockbauer, $R$.

Member, Office Automation Committee, American Vacuum Society

Co-Chairman, Topical Conference on High Temperature Superconducting Thin Films, American Vacuum Society National Symposium, Boston, MA, October, 1989

Consultant, Abstract Processing Computer Database, American Vacuum Society 


\section{PROFESSIONAL INTERACTIONS, CONSULTING AND ADVISORY SERVICES}

Camus, P. P.

Collaborating (with A. J. Melmed) with Dr. R. D. Shull of the NIST

Metallurgy Division on composition and structural measurements on a nanometer scale of magnetic thin-film composites.

Collaborating (with A. J. Melmed) with Dr. C. K. Chiang of the NIST Ceramics Division on studies of stoichiometries and compositional inhomogeneities of high-temperature superconducting oxides.

Cavanagh, R. R.

Collaborating with Dr. D. S. King of the NIST Molecular Spectroscopy

Division on state-specific diagnostics of molecular desorption processes.

Collaborating with Drs. J. C. Stephenson, E. J. Heilweil, and M. P. Casassa of the NIST Molecular Spectroscopy Division on time-resolved measurements of vibrational relaxation processes at surfaces.

Collaborating with Drs. J. J. Rush, J.'M. Nicol, and T. J. Udovic of the NIST Reactor Radiation Division on quasi-elastic neutron scattering studies of adsorbates on high-surface-area materials.

Egelhoff, Jr., W. F.

Collaborating with Drs. W. Schwarzacher, W. Allison, R. F. Willis, and $\mathrm{J}$. Penfold of Cambridge University, England to make neutron scattering measurements of the absolute magnetic moment of epitaxial $\mathrm{Fe}-\mathrm{Cu}$ structures prepared at NIST.

Collaborating with Dr. W. Schwarzacher of Cambridge University, England and Drs. J. Lecante and D. Chandesrif of the Orsay Synchrotron, France on extended $x$-ray absorption fine structure measurements of epitaxial $\mathrm{Fe}-\mathrm{Cu}$ structures prepared at NIST.

Collaborating with Drs. B. Heinrich, J. Cochran, and J. Dutcher of Simon Fraser University, Canada on ferromagnetic resonance measurements of the magnetocrystalline anisotropy of epitaxial $\mathrm{Fe}-\mathrm{Cu}$ structures prepared at NIST.

Fine, J. Collaborating with Dr. I. Terzic of the Boris Kidric Institute, Belgrade, Yugoslavia on electronic excitation and electron emission for ion-bombarded surfaces. This collaboration is conducted under the auspices of the U.S. -Yugoslavia Agreement for Cooperation in Science and Technology. 
Collaborating with Drs. L. and N. Tanovic of the University of Sarajevo, Yugoslavia on characterizing surface topography changes that result from ion bombardment. This collaboration is conducted under the auspices of the U.S. -Yugoslavia Agreement for Cooperation in Science and Technology.

Collaborating with Dr. T. Nenadovic of the Boris Kidric Institute, Belgrade, Yugoslavia on the surface topography effect of both particle and laser-beam interactions with thin solid films. This collaboration is conducted under the auspices of the U.S.-Yugoslavia Agreement for Cooperation in Science and Technology.

Collaborating with Dr. J. D. Fassett of the NIST Inorganic Analytical Research Division on the use of laser multiphoton-ionization techniques to identify sputtered atoms and to determine their kinetic energies.

Collaborating with Dr. W. Kirchhoff of the Department of Energy on a data analysis procedure for sputter-depth-profile interface characterization.

Collaborating with Drs. C. Le Gressus and J. P. Duraud of the Centre d'Etudes Nucleaires, Saclay, France on the collosional excitation and electron decay of atoms at single-crystal surfaces.

Collaborating with Dr. P. "Roncin of the Universite Paris, CNRS/Orsay, France on the use of laser multiphon-ionization techniques to identify sputtered atoms and to determine their kinetic energies.

Collaborating with $\mathrm{Dr}$. M. H. Shapiro of the California State University at Fullerton on multiple-interaction calculations of ion-induced collisional atomic excitation and ejection at single-crystal surfaces.

Collaborating with Dr. R. Freemire of the NIST Center for Computing and Applied Mathematics on generating computer movies from the results of calculations of ion-surface collisional excitations and ejection trajectories.

Collaborating with Dr. G. P. Chambers of the Naval Research Laboratory, Washington, D.C. on the compilation and evaluation of absolute sputtering yield data.

Collaborating with Dr. M. Szymonski of the Jagellonian University, Krakow, Poland on energy distributions of collisionally excited and ejected atoms at surfaces.

Collaborating with $\mathrm{Dr}$. D. Lo of the Institute for Defense Analysis, Alexandria, VA on multiple interaction calculations of collisional excitation and ejection processes of atoms located on single-crystal surfaces as a probe of site geometry. 
Collaborating with Dr. V. C. Kannan of the AT\&T Laboratories, Allentown, PA on structure characterization of NIST SRM 2135 by transmission electron microscopy and $x$-ray diffraction.

Collaborating with Drs. L. Holdeman and E. Sparks of COMSAT, Germantown, MD on the fabrication and characterization of new batches of $\mathrm{Ni} / \mathrm{Cr}$ thin-film structures intended for use as SRM 2135.

Gadzuk, J. W.

Collaborating with Prof. M. Sunjic of the Ruder Boskovic Institute and the University of Zagreb, Yugoslavia on theories of electron spectroscopies and dynamics of molecular processes at surfaces. This collaboration is conducted under the auspices of the U.S.-Yugoslavia Agreement for Cooperation in Science and Technology.

Collaborating with Dr. S. Holloway, University of Liverpool, England on theories of molecular processes at surfaces. This collaboration is assisted by a grant from the NATO Scientific Affairs Division.

Collaborating with $\mathrm{Dr}$. N. Sathyamurthy, Indian Institute of Technology, Kanpur, India, and serving a monitor for a project "Chemical Dynamics and Laser Spectroscopy", under the auspices of the India-U.S. Materials Science Program funded via the provisions of PL- 480 .

Collaborating with Dr. C. W. Clark of the NIST Radiation Physics Division on atomic physics aspects of resonance-enhanced electronstimulated desorption.

Consulted with Prof. B. Cooper of Cornell University on topics related to charge transfer in ion-beam scattering from surfaces.

Consulted with Prof. J. K. Nørskov of the Technical University of Denmark on problems associated with theoretical modeling of molecular processes at surfaces.

Served as an invited discussion leader at the Gordon Research Conference on Dynamics of Gas-Surface Interactions.

Jach, T.

Collaborated with Drs. M. B. Bedzyk and Q. Shen of Cornell University on grazing-angle $x$-ray diffraction experiments at surfaces.

Collaborated with Dr. L. B. Holdeman of COMSAT and Dr. G. Hembree of Arizona State University on reflection electron microscopy studies of the growth of thin gold films.

Collaborated with Drs. J. Geist, D. Novotny, and G. P. Carver of the NIST Semiconductor Electronics Division on the development of novel semiconductor devices for $x$-ray experiments.

Collaborated with Dr. R. Crandall of the Solar Energy Research Institute on the fabrication of silicon $\mathrm{x}$-ray detectors. 
Collaborated with Drs. D. W. Lindle, P. L. Cowan, R. E. LaVilla, and R. D. Deslattes of the NIST Quantum Metrology Division and Dr. R. C. C. Perera of Lawrence Berkeley Laboratory on analysis of atomic and molecular spectra obtained with x-ray excitations at the Brookhaven National Synchrotron Light Source.

Collaborated with Drs. J. R. Patel, F. Sette, P. H. Citrin, J. E. Rowe, and D. W. Berreman of AT\&T Bell Laboratories and Dr. P. L. Cowan of the NIST Quantum Metrology DIvision on back-reflection x-ray standing-wave experiments.

Joyce, S. A.

Collaborating (with L. J. Whitman and J. A. Yarmoff) with Dr. F. R. McFeely of the IBM Watson Research Center on studies of semiconductor surface deposition and etching reactions.

Kurtz, R. L.

Collaborating with Prof. J. L. de Segovia and Dr. E. Roman-Garcia of the Instituto Ciencia de Materiales, CSCIC, Madrid on a study of the electronic structure and molecular adsorption of $\mathrm{H}_{2} \mathrm{O}$ and $\mathrm{NH}_{3}$ at low temperatures on transition-metal oxide surfaces.

Collaborating with Dr. A. Shih of the Naval Research Laboratory in photoemission and ion desorption studies of $\mathrm{Ba}$ and $\mathrm{BaO}$ on $\mathrm{W}$ as model systems for high-emission dispenser cathodes.

Collaborating with Dr. R. Walkup of IBM in studies of ion desorption using molecular dynamics calculations to predict surface reconstructions, stability of various defect structures, and iondesorption trajectories.

Melmed, A. J.

Collaborating (with P. P. Camus) with Dr. C. K. Chiang of the NIST Ceramics Division on studies of stoichiometries and compositional inhomogeneities of high-temperature superconducting oxides.

Collaborating (with P. P. Camus) with Dr. R. D. Shull of the NIST Metallurgy Division on composition and structural measurements on a nanometer scale of magnetic thin-film composites.

Collaborating with Dr. H. A. Fowler of the NIST Mathematical Analysis Division on simulations of field-ion-microscopy images.

Collaborating with Drs. N. Ernst and W. A. Schmidt of the Fritz-HaberInstitute, West Berlin, FRG on studies of the electronic structure of high- $T_{c}$ superconducting materials.

Collaboration with Dr. W. Drachsel of the Fritz-Haber-Institute, Berlin, FRG on the performance of a reflectron lens for increasing the mass resolution of an atom probe. 
Powell, C. J.

Collaborating with Drs. J. K. N. Sharma and S. M. Shivaprasad of the Indian National Physical Laboratory, under the auspices of the U.S.India Cooperative Program, on experimental studies of metalsemiconductor interfaces.

Collaborating with Dr. D. R. Penn of the NIST Electron Physics Group and Dr. S. Tanuma of the Nippon Mining Company, Japan on calculations of the inelastic mean free paths of low-energy electrons in solids.

Collaborating with Dr. M. P. Seah of the UK National Physical Laboratory on an analysis of the factors affecting the accuracy and precision of quantitative surface analyses of Auger-electron spectroscopy and $x$-ray photoelectron spectroscopy.

Collaborating with Dr. M. P. Seah of the UK National Physical Laboratory on the development of plans and programs for the Surface Chemical Analysis Technical Working Party of the Versailles Project on Advanced Materials and Standards.

Adjudicator for the Science Prize of the UK ESCA Users Group.

Robey, S. W.

Collaborating with Dr. L. H. Bennett of the NIST Magnetic Materials Group on resonant photoemission investigations of half-metallic ferromagnetic materials.

Stiles, M. D.

Collaborating with Dr. D. R. Hamann of AT\&T Bell Laboratories on calculations of ballistic electron transport through interfaces.

Collaborating with Dr. D. R. Penn of the NIST Electron Physics Group and Dr. S. M. Girvin of Indiana University on studies of Coulomb blockade effects.

Whitman, L. J.

Collaborating (with S. A. Joyce and J. A. Yarmoff) with Dr. F. R. McFeely of the IBM Watson Research Center on studies of semiconductor surface deposition and etching reactions.

Yarmoff, J. A.

Collaborating (with S. A. Joyce and L. J. Whitman) with Dr. F. R. McFeely of the IBM Watson Research Center on studies of semiconductor surface deposition and etching reactions.

Collaborating with $\mathrm{Dr}$. J. R. Lince of The Aerospace Corporation on studies of the surface chemistry of $\mathrm{MoS}_{2}$. 


\section{GUEST SCIENTISTS}

The Surface Science Division has been host during the past year to a number of scientists who have worked with the Division staff on problems of mutual interest.

Blaisten-Barojas, E., Professor of Physics at the National University of Mexico, at NIST for four months beginning in September, 1988 on theoretical studies of coupled electronic and vibrational excited states of molecule/cluster systems.

Chambers, G. P., a graduate student at and then a graduate of the University of Maryland, has worked at NIST for six years, beginning in January, 1983 under a cooperative agreement. He has been involved in the compilation of evaluated sputtering yield data.

Elswijk, H. B., of the University of Groningen, The Netherlands worked at NIST for ten months beginning in June, 1988 on studies of the microcomposition and microstructure of $\mathrm{High}-\mathrm{T}_{\mathrm{c}}$ superconducting materials.

Marton, D., of the Technical University of Budapest, Hungary has worked at NIST over most of the past thrée years to determine the interface-width dependence in the depth profiling of thin films on topographic changes during sputtering, to determine effects of radiation-enhanced diffusion on depth profiles, to characterize thin-film systems as standard reference materials, and to develop a scanning scattering microscope.

Mintz, M., of the Ben Gurion University of the Negev, Israel worked one year at NIST beginning August, 1988 performing experiments to measure kinetic energy distributions of sputtered neutral atoms and the detection of evaporating atoms with very low vapor pressures.

Mueller, D. R., of the Naval Research Laboratory worked at NIST for two and a half years through October, 1988 on photoemission studies of high- $\mathrm{T}_{\mathrm{c}}$ superconducting materials.

Roman-Garcia, E., of the Instituto Ciencia de Materiales, CSIC, Madrid worked at NIST for three months beginning October, 1988 on photoemission studies of the effects of defects on chemisorption on $\mathrm{TiO}_{2}$ surfaces.

Shapiro, M. H., a Professor of Physics at the California State University at Fullerton, has worked at NIST on an occasional basis during the two years beginning September, 1987 on multiple-interaction calculations of ion-surface collisions.

Shih, A., of the Naval Research Laboratory has worked at NIST during the two years since February, 1987 on photoemission experiments to characterize high- $T_{c}$ superconducting materials. 
Thurgate, S. M., of Murdoch University, Perth, Western Australia worked at NIST for eight months beginning March, 1988 on experiments to study the oxidation of indium phosphide and on the design and construction of an experiment to measure the shifts of core-level binding energies for surface atoms by grazing-angle photoemission.

Wang, Q., Fudan University, Shanghai, Peoples Republic of China worked at NIST for two years beginning June, 1987 on experiments to measure electron attenuation lengths in condensed molecular solids. 

follows :

As of September 30, 1989 the Surface Science Division was staffed as

C. J. Powell, Chief,

L. M. Johnson, Secretary

N. M. Selepak, Clerk-Typist

Surface Dynamical Processes Group

R. R. Cavanagh, Group Leader

J. D. Beckerle*

P. M. Connelly\#

S. A. Buntin"

S. A. Joyce

R. L. King ${ }^{+}$

R. L. Kurtz

T. E. Madey@

E. O. Neitzel"

D. E. Ramaker $r^{\theta}$

L. J. Richter

S. W. Robey

R. L. Stockbauer ${ }^{8}$

L. J. Waltman

J. A. Yarmoff

Thin Films and Interfaces Group

W. F. Egelhoff, Jr., Group Leader

P. P. Camus

T. J. Jach

A. J. Melmed

M. D. Stiles

Surface Spectroscopies and Standards Group

C. J. Powell, Group Leader

J. Fine

J. W. Gadzuk

* NIST-NRC Postdoctoral Research Associate

( Faculty Appointment, intermittent

* Engineering Technician

+ Electronics Technician

a Contractor 

NBS.114A REV. 2.8C)

U.S. DEPT. OF COMM.

BIBLIOGRAPHIC DATA

SHEET (See instructions)

1. PUBLICATION OR

REPORT NO.

NISTIR $89-4224$

2. Performing Organ. Report Nof 3. Publication Date

January 1990

4. TITLE AND SUBTITLE

Technical Activities 1989

Surface Science Division

5. $A \cup T H O R(S)$

C. J. Powell, editor

6. PERFORMING ORGANIZATION (If joint or other than NBS, see instructions)

7. Contract Grant No.

NATIONAL BUREAU OF STANDARDS

U.S. DEPARTMENT OF COMMERCE

GAITHERSBURG, MD 20899

9. SPONSORING ORGANIZATION NAME AND COMPLETE ADDRESS (Street, City, State, ZIP)

8. Type of Report \& Period Covered

10. SUPPLEMENTARY NOTES

Document describes a computer program; SF-185, FIPS Software Summary, is attached.

11. ABSTRACT (A 200-word or less foctual summory of most significont informotion. If document includes a significant bibliogrophy or literoture survey, mention it here)

This report summarizes technical activities of the NIST Surface Science Division during Fiscal Year 1989. These activities are in three principal areas: surface dynamical processes, thin films and interfaces, and surface spectroscopies and standards. A listing is given of publications, talks, professional comittee participation, and professional interactions by the Division staff.

12. KEY WORDS (Six to twelve entries; alphabetical order; copitalize only proper names; and seporate key words by semicolons) surface chemistry; surface physics; surface science; surface standards

13. AVAILABILITY

XXV Unlimited

For Official Distribution. Do Not Release to NTIS

Order From Superintendent of Documents, U.S. Government Prinung Office, Washington, D.C. 20402.

XX Order From National Technical Information Service (NTIS), Springfield, VA. 2216i
14. NO. OF PRINTED PAGES 68

15. Price

$\mathrm{AO}_{4}$ 

$>$ 
